\title{
Relationship between variability of the semidiurnal tide in the Northern Hemisphere mesosphere and quasi-stationary planetary waves throughout the global middle atmosphere
}

\author{
X. Xu ${ }^{1}$, A. H. Manson ${ }^{1}$, C. E. Meek ${ }^{1}$, T. Chshyolkova ${ }^{1}$, J. R. Drummond ${ }^{2}$, C. M. Hall ${ }^{3}$, Ch. Jacobi ${ }^{4}$, D. Riggin ${ }^{5}$, \\ R. E. Hibbins ${ }^{6}$, M. Tsutsumi ${ }^{7}$, W. K. Hocking ${ }^{8}$, and W. E. Ward ${ }^{9}$ \\ ${ }^{1}$ Institute of Space and Atmospheric Studies, University of Saskatchewan, Saskatoon, Canada \\ ${ }^{2}$ Physics and Atmospheric Science Department, University of Dalhousie, Halifax, Canada \\ ${ }^{3}$ Troms $\varnothing$ Geophysical Observatory, University of Troms $\varnothing$, Troms $\varnothing$, Norway \\ ${ }^{4}$ Institute for Meteorology, University of Leipzig, Germany \\ ${ }^{5}$ Colorado Research Associates, Boulder, USA \\ ${ }^{6}$ British Antarctic Survey, Cambridge, UK \\ ${ }^{7}$ National Institute for Polar Research, Tokyo, Japan \\ ${ }^{8}$ Physics and Astronomy Department, University of Western Ontario, London, Canada \\ ${ }^{9}$ Physics and Astronomy Department, University of New Brunswick, Fredericton, Canada
}

Received: 7 May 2009 - Revised: 5 November 2009 - Accepted: 9 November 2009 - Published: 11 November 2009

\begin{abstract}
To investigate possible couplings between planetary waves and the semidiurnal tide (SDT), this work examines the statistical correlations between the SDT amplitudes observed in the Northern Hemisphere (NH) mesosphere and stationary planetary wave (SPW) with wavenumber $\mathrm{S}=1$ (SPW1) amplitudes throughout the global stratosphere and mesosphere. The latter are derived from the Aura-MLS temperature measurements. During NH summerfall (July-October), the mesospheric SDT amplitudes observed at Svalbard $\left(78^{\circ} \mathrm{N}\right)$ and Eureka $\left(80^{\circ} \mathrm{N}\right)$ usually do not show persistent correlations with the SPW1 amplitudes in the opposite hemisphere. Although the SDT amplitudes observed at lower latitudes $\left(\sim 50-70^{\circ} \mathrm{N}\right)$, especially at Saskatoon $\left(52^{\circ} \mathrm{N}\right)$, are often shown to be highly and positively correlated with the SPW1 amplitudes in high southern latitudes, these correlations cannot be sufficiently explained as evidence for a direct physical link between the Southern Hemisphere (SH) winter-early spring SPW and NH summer-early fall mesospheric SDT. This is because the migrating tide's contribution is usually dominant in the mid-high latitude $\left(\sim 50-70^{\circ} \mathrm{N}\right) \mathrm{NH}$ mesosphere during the local late summerearly fall (July-September). The numerical correlation is dominated by similar low-frequency variability or trends between the amplitudes of the NH SDT and SH SPW1 during the respective equinoctial transitions. In contradistinction,
\end{abstract}

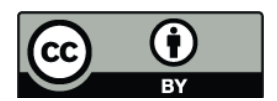

Correspondence to: $\mathrm{X} . \mathrm{Xu}$

(xix303@mail.usask.ca) during NH winter (November-February), the mesospheric SDT amplitudes at northern mid-high latitudes $\left(\sim 50-80^{\circ} \mathrm{N}\right)$ are observed to be significantly and positively correlated with the SPW1 amplitudes in the same hemisphere in most cases. Because both the SPW and migrating SDT are large in the $\mathrm{NH}$ during the local winter, a non-linear interaction between SPW and migrating SDT probably occurs, thus providing a global non-migrating SDT. This is consistent with observations of SDT in Antarctica that are large in summer than in winter. It is suggested that climatological hemispheric asymmetry, e.g. the $\mathrm{SH}$ and $\mathrm{NH}$ winter characteristics are substantially different, lead to differences in the inter-hemispheric SPW-tide physical links.

Keywords. Meteorology and atmospheric dynamics (Middle atmosphere dynamics; Polar meteorology; Waves and tides)

\section{Introduction}

Examination of the correlation between the tide and planetary waves (PWs) is an important issue for understanding possible sources of the tidal amplitude variability. Presently, such a relationship can be physically interpreted as the nonlinear interaction between the migrating tide (MT) and (quasi-) stationary planetary wave (SPW), which produces the non-migrating tides (NMT) (e.g. Hagan and Roble, 2001; Angelats i Coll and Forbes, 2002; Manson et al., 2009).

Published by Copernicus Publications on behalf of the European Geosciences Union. 
Non-migrating tides have been found to be non-negligible at high latitudes in model studies (Miyahara and Miyoshi, 1997; Miyahara et al., 1999; Yamashita et al., 2002). Earlier observational studies for non-migrating tides were centered on the South Pole (Hernandez et al., 1993; Forbes et al., 1995; Portnyagin et al., 1998). Hernandez et al. (1993) used $\mathrm{OH}$ emissions for several winter-years to identify a 12$\mathrm{h}$ oscillation of $\mathrm{s}=1$ over the South Pole. A meteor radar at $90^{\circ} \mathrm{S}$ that used orthogonal antennas provided confirmation of a 12-h NMT with $\mathrm{s}=1$, and their preference for process was non-linear interactions with the local summer SPW with $\mathrm{S}=1$ (SPW1) (Forbes et al., 1995). The $\mathrm{s}=1$ semidiurnal tide (SDT) occurs most often during austral summer. With the $90^{\circ} \mathrm{S}$ data and radar data from Scott Base $\left(78^{\circ} \mathrm{S}\right)$, Molodezhnaya $\left(68^{\circ} \mathrm{S}\right)$ and Mawson $\left(67^{\circ} \mathrm{S}\right)$, Portnyagin et al. (1998) found that at the South Pole the 12-h oscillations were consistent with a NMT of $s=1$ for spring-summer months. Away from the pole, the 12-h oscillation at Scott Base $\left(78^{\circ} \mathrm{S}\right)$ was also consistent with a dominant NMT of $s=1$ and shared spring-summer maximum amplitudes with the South Pole. In contrast, at $\sim 70^{\circ} \mathrm{S}$ the semidiurnal tides (SDTs) had maximum equinoctial amplitudes and a mixture of MT $(s=2)$ and NMT ( $s=1$ ) was suggested. Consistent with this, the studies by Riggin et al. (1999) and Portnyagin et al. (2000) concluded that the $s=1$ semidiurnal oscillation observed at the South Pole during austral summer may extend equatorward to somewhat lower latitudes $\left(\sim 80^{\circ} \mathrm{S}\right)$. And Murphy (2002) has also showed that a combination of $s=1$ and $s=2$ modes might explain rapid fluctuations in the phase of the 12 -h component of MF radar winds observed at Davis $\left(69^{\circ} \mathrm{S}, 78^{\circ} \mathrm{E}\right)$. Most recently, Murphy et al. (2006) used several Antarctic radars to identify a dominant semidiurnal NMT of $s=1$ (and a lesser $s=0$ ) during Southern Hemisphere $(\mathrm{SH})$ summerequinox months (October-March). The regional average latitude was $69^{\circ} \mathrm{S}$. Based on four years of radar wind data from Halley $\left(76^{\circ} \mathrm{S}, 26^{\circ} \mathrm{W}\right)$ and Scott Base $\left(78^{\circ} \mathrm{S}, 167^{\circ} \mathrm{E}\right)$, Baumgaertner et al. (2006) demonstrated that the $\mathrm{s}=1 \mathrm{SDT}$ is often dominant in summer, while in winter a mixture of $s=1$ and $\mathrm{s}=2$ is found.

The situation in the Northern Hemisphere (NH) is shown to be different. Manson et al. (2009), based upon analysis of the Svalbard and Eureka tides during 2006/2007, showed that at latitudes near $80^{\circ} \mathrm{N}$ the semidiurnal MT $(\mathrm{s}=2)$ is dominant in summer, while the semidiurnal NMT with $s=1$ and $s=3$ occur most often during equinoctial or early summer months. Portnyagin et al. (2004) examined the slopes of the tidal phases (time of maximum in UT) versus longitudes and concluded that in the southern Arctic $\left(65-75^{\circ} \mathrm{N}\right)$ the migrating tides are dominant for both diurnal and semidiurnal oscillations during all months, but with some indications of NMT in May-June. Riggin et al. (2003) also showed that during the summer-early fall months (June-September) the SDT at the latitudes of Andenes $\left(69^{\circ} \mathrm{N}, 16^{\circ} \mathrm{E}\right)$ and Poker Flat $\left(65^{\circ} \mathrm{N}\right.$, $147^{\circ} \mathrm{W}$ ) usually has a zonal wave number 2 (MT) structure. Forbes and $\mathrm{Wu}$ (2006) discussed the global tidal field $\left(70^{\circ} \mathrm{S}-70^{\circ} \mathrm{N}\right)$ using temperatures from UARS-MLS (19911997) at heights of $25-86 \mathrm{~km}$ and suggested minimal presence of semidiurnal $s=1$ thermal tide at high northern latitudes (their Fig. 11), although the latitudinal structures of NMT and "expansion functions" for winds and temperature do differ. Manson et al. (2004a) concluded that the semidiurnal NMT was weak compared with the semidiurnal MT in summer and fall for latitudes near $70^{\circ} \mathrm{N}$ using HRDI-UARS wind data near $95 \mathrm{~km}$. For the mid-latitudes $\left(\sim 40^{\circ} \mathrm{N}\right)$ and at altitudes above $80 \mathrm{~km}$, the migrating SDT dominates in the region of late-summer/fall maximum amplitude (Manson et al., 2006). Overall, the non-migrating tides in the $\mathrm{SH}$ are clearly stronger than in the $\mathrm{NH}$ during the summer months of each hemisphere. Aso (2007) also suggested that a hemispheric asymmetry might then exist in the seasonal variations of the semidiurnal NMT $s=1$ after discussing the asymmetry of the SPW1 activity between the NH and SH.

There is growing evidence in recent years for the interhemispheric SPW-tidal connections. The model study of Yamashita et al. (2002) verified that the nonlinear interaction forcing between the SPW1 and the migrating SDT could provide the non-migrating SDT $(s=1)$. Their related calculations with this tide indicated that, once excited in the $\mathrm{NH}$ winter hemisphere, it could propagate to the polar mesosphere and lower thermosphere (MLT) region of the SH and result in the local summer enhancement of the $s=1$ SDT. Recently, Aso (2007) assessed the semidiurnal NMT at polar latitudes using a linearized steady and explicit tidal model and confirmed the trans-equatorial propagation of the 12-h NMT with $\mathrm{s}=1$, which is forced in the opposite winter hemisphere. Baumgaertner et al. (2005) compared the seasonal sequences of planetary wave amplitudes with amplitudes of the SDT at Scott Base $\left(78^{\circ} \mathrm{S}, 167^{\circ} \mathrm{E}\right)$ and pointed out that planetary waves in both the $\mathrm{SH}$ and $\mathrm{NH}$ are partly responsible for the seasonal variability of the $\mathrm{SH}$ semidiurnal tide via the generation of a $\mathrm{s}=1 \mathrm{SDT}$. Based on observations using two radars, located at Scott Base and at Halley $\left(76^{\circ} \mathrm{S}, 26^{\circ} \mathrm{W}\right)$, Baumgaertner et al. (2006) further showed that the amplitudes of the semidiurnal NMT $(\mathrm{s}=1)$ were positively correlated with the NH SPW1 near $1 \mathrm{hPa}$ during the SH summer months, but also with the SH SPW1 near $10 \mathrm{hPa}$ during the SH winter period. During the reviewing process of this paper, it was learned that Murphy et al. (2009) has used amplitudes of the SH semidiurnal NMT $s=1$ and 3 during summer and early fall, obtained from 4 radars, to demonstrate correlations with the global planetary wave $(S=1)$ and hence source regions in the NH. Thus these new results are consistent with those of Baumgaertner et al. (2005, 2006), who used two radars, as is our situation in the $\mathrm{NH}$.

Recently, Smith et al. (2007) found a correlation between variability of the mesospheric SDT at Esrange $\left(68^{\circ} \mathrm{N}, 21^{\circ} \mathrm{E}\right)$ and the amplitude of planetary wave number $\mathrm{S}=1$ ( $\mathrm{PW} 1$, quasi-stationary) in the SH stratosphere and lower mesosphere during NH summer and fall. Based on their hypothesis, the correlation implied that the non-migrating tide had 
a significant contribution to the tidal variability observed at Esrange and that the autumn enhancement of the Esrange SDT was associated with the growth of the SH PW. Their interpretation is that the PW in the SH interacts with the global semidiurnal migrating tide and produces nonmigrating semidiurnal tides that vary in time in concert with the SH PW.

Although the differences between the observed tidal amplitudes and the predictions of the Global Scale Wave Model (GSWM) for summer-autumn may indicate the presence of nom-migrating tides at Esrange (Mitchell et al., 2002), the migrating SDT usually dominates for nearly all months in the latitudes of $\sim 70^{\circ} \mathrm{N}$ in the MLT region based on the descriptions given earlier. In particular the strong early-autumn enhancement at mid-high northern latitudes is definitely the characteristic of the migrating SDT (Riggin et al., 2003) which experiences favourable winds and refractive indices at these times. Hence, doubts have been cast on the physical significance for the correlations found by Smith et al. (2007). On the other hand, the Pearson correlation coefficient is a measure of a linear relationship integrated over an interval and over all frequencies; information on the temporal dependence of variables and time scales relevant to correlations cannot be seen in this integrated analysis. We know that both the SPW and tidal sequences have strong seasonality. The strong seasonality would easily lead to a high correlation coefficient, even though the physical relationship between the two variables is not real. Therefore, the question, of whether the correlations found by Smith et al. (2007) implied SPWtidal nonlinear interactions or were induced by the numerical problems of seasonal trend, comes up. Further, if the correlation implies that the non-migrating component contributes a significant part to the tidal variability at $\sim 70^{\circ} \mathrm{N}$, the non-migrating tides could be stronger and even dominate at Arctic latitudes $\left(\sim 80^{\circ} \mathrm{N}\right)$ and could be weaker at lower latitudes $\left(\sim 50^{\circ} \mathrm{N}\right)$ based upon the Antarctic data as discussed above. Then the observed tidal amplitudes at appropriate longitudes at Arctic latitudes (lower latitudes) would have stronger (weaker) correlations with the SH SPW amplitudes. The aim of this paper is to clarify this question by further analysis of the relationship between the variability of the SDT in the NH mesosphere and the global SPW1 amplitudes with considerations of the longitudinal and latitudinal variations of the SDT.

Here the SDT data are derived using medium frequency radars (MFR) at Saskatoon $\left(52^{\circ} \mathrm{N}, 253^{\circ} \mathrm{E}\right)$, Troms $\varnothing\left(70^{\circ} \mathrm{N}\right.$, $\left.19^{\circ} \mathrm{E}\right)$, and meteor radars (MWR) at Collm $\left(51^{\circ} \mathrm{N}, 13^{\circ} \mathrm{E}\right)$, Eureka $\left(80^{\circ} \mathrm{N}, 86^{\circ} \mathrm{W}\right)$ and Svalbard $\left(78^{\circ} \mathrm{N}, 16^{\circ} \mathrm{E}\right)$. The relative importance of migrating and non-migrating SDTs at polar latitudes and at high mid-latitudes is estimated based upon the observations from the Svalbard-Eureka pair and the Collm-Saskatoon pair. The Aura-MLS temperature measurements with near global view (latitude coverage $82^{\circ} \mathrm{S}-$ $82^{\circ} \mathrm{N}$ ) are used to construct the global stationary planetary wave field. The data and analysis technique are briefly de- scribed in Sect. 2. In Sect. 3 and Sect. 4 the tidal variability is compared with the SPW throughout the global middle atmosphere. Section 5 simply discusses the time scale relevant to the correlation. Finally a discussion and summary will be made in Sect. 6, followed by conclusions in Sect. 7.

\section{Data description and analysis technique}

\subsection{Radar data}

The tidal data for this study are taken from MF radars at Saskatoon $\left(52^{\circ} \mathrm{N}, 253^{\circ} \mathrm{E}\right)$, Troms $\varnothing\left(70^{\circ} \mathrm{N}, 19^{\circ} \mathrm{E}\right)$, and meteor radars at Collm $\left(51^{\circ} \mathrm{N}, 13^{\circ} \mathrm{E}\right)$, Eureka $\left(80^{\circ} \mathrm{N}, 86^{\circ} \mathrm{W}\right)$ and Svalbard $\left(78^{\circ} \mathrm{N}, 16^{\circ} \mathrm{E}\right)$. A detailed description of these radars can be found in Chshyolkova et al. (2007) and Manson et al. (2009). In this study, the radar data are usually analysed at 6 height levels centered on 82, 85, 88, 91, 94 and $97 \mathrm{~km}$. The semidiurnal tides are obtained by a least-squares fit of the mean, 48-, 24-, 12-, 8- and 6-h components to the hourly mean radar measurements. The fitting uses a window of 4 days shifted by 1 day. It is required that for each fit there be data for 16 or more local hours out of 24 for each height over the window. Tides at $85,91,97 \mathrm{~km}$ are usually similar to tides at 82,88 and $94 \mathrm{~km}$, respectively. In addition, the difference between the meridional (NS) and zonal (EW) components is small for the SDT amplitude (e.g. Manson et al., 2009). Hence, to save space, only analyses related to the meridional (NS) semidiurnal tides (SDTs) at 82, 88 and $94 \mathrm{~km}$ are shown in this study.

With two sites at similar latitudes and widely separated longitudes, it is possible to solve for the amplitude and phase of two tides (e.g. Baumgaertner et al., 2006; Manson et al., 2009). Assuming one of the two tides is a migrating tide ( $\mathrm{s}=2$ for the SDT), and that the forcing of the NMT near $80^{\circ} \mathrm{N}$ is due to wave numbers $S=1$ or 2, pairs of the MT and chosen NMT values were calculated (Manson et al., 2009). The latitude difference between Svalbard and Eureka is about 2 deg, allowing us to fit a migrating and non-migrating tide with a given wavenumber to the data from these two sites. The same is true for the Collm-Saskatoon pair. Manson et al. (2009) showed strong amplitude and phase differences between the semidiurnal tides observed at the two Arctic radars throughout 12 months of 2006/2007 [also for the diurnal tides]. This was argued to be consistent with dominance of semidiurnal NMT $s=+1$ in the spring and early summer, and dominance of diurnal NMT $s=0$ or +2 in the winter and spring. A significant disadvantage for the 'two radar' scenario, sometimes inescapable due to the absence of land mass in the $\mathrm{NH}$, is the inability to locate the longitude of constructive interference (see Discussion of Sect. 6). Here, given that we are most interested in the relative importance of MT and NMT, plus that there are other possible choices for the forcing of NMT at $51 / 52^{\circ} \mathrm{N}$ (e.g. Manson et al., 2004a, b), the percentagepower of the MT (e.g. Fig. 12 from Manson et al., 2009) 
is provided as an alternative to providing the MT and chosen wave-numbered NMT amplitudes. A reviewer had also raised concerns, in particular regarding the NMT forcing at middle latitudes, and the study is not harmed by their absence.

The measured value $v$ (e.g. of tidal wind), at any longitude $L$ can be written as

$v=A_{L} \cos \left(n \Omega t-\phi_{L}\right)=\sum_{s} A_{s} \cos \left(n \Omega t+s L-\phi_{S}\right)$

where $n$ is the frequency in cycles per day ( $n=2$ for a SDT), $\Omega=2 \pi / 24.0, t$ is the UT. $s$ is the zonal wavenumber; westward (eastward) prorogation tides have positive (negative) $s, A$ and $\phi$ are the amplitude and phase (the UT of maximum northward/eastward tidal wind). For the fitting of single mode from two sites,

$$
\begin{aligned}
& A_{K} \cos \phi_{K}=C_{1} \cos \left(s L_{K}\right)+C_{2} \sin \left(s L_{K}\right) \\
& A_{K} \sin \phi_{K}=-C_{1} \sin \left(s L_{K}\right)+C_{2} \cos \left(s L_{K}\right) \\
& A_{B} \cos \phi_{B}=C_{1} \cos \left(s L_{B}\right)+C_{2} \sin \left(s L_{B}\right) \\
& A_{B} \sin \phi_{B}=-C_{1} \sin \left(s L_{B}\right)+C_{2} \cos \left(s L_{B}\right)
\end{aligned}
$$

where data are from sites " $\mathrm{K}$ " and "B", and $C_{1}=A_{s} \cos \phi_{s}$; $C_{2}=A_{s} \sin \phi_{s}$. We fit a migrating tide (s=2) to "K" and "B" tidal parameters by the least squares method and get the migrating tide's amplitude $A_{s}$ and phase $\phi_{s}$. Empirically we define the "percentage power in the MT" as $2 A_{s}^{2} /\left(A_{K}^{2}+A_{B}^{2}\right)$, so that a percentage-power with value close to $100 \%$ means the dominance of the MT.

\subsection{Aura-MLS temperature}

The temperatures used here are version 2.2 data from the Microwave Limb Sounder (MLS) on board the National Aeronautic and Space Administration (NASA) Aura satellite. The data are available starting in August 2004 and have latitude coverage from $82^{\circ} \mathrm{S}$ to $82^{\circ} \mathrm{N}$. The useful altitude range is $316-0.001 \mathrm{hPa}(\sim 8-97 \mathrm{~km})$ with precision ranging from $0.6 \mathrm{~K}$ in the lower stratosphere to $2.5 \mathrm{~K}$ in the mesosphere. More information on Aura-MLS data was provided in Chshyolkova et al. (2007). In this paper, the temperatures are sorted into cells with $5^{\circ}$ width in latitude and $20^{\circ}$ width in longitude. The SPW field is then constructed by a Fourier analysis on a window of 4 days shifted by 1 day, which is consistent with the tidal analyses. This technique is reasonable and reliable for the stratosphere and lower mesosphere given the negligible aliasing effect from non-migrating tides. Note the PW1 is usually shown as being quasi-stationary in both hemispheres (Leovy and Webster, 1976).

\section{Correlation analyses between the SH SPW1 and NH SDT amplitudes during NH summer-fall}

This section will present the height-latitude contour plots of the linear correlation coefficient (also called the Pearson correlation coefficient) for the SPW1 amplitudes throughout the global $\left(82^{\circ} \mathrm{S}-82^{\circ} \mathrm{N}\right)$ stratosphere and mesosphere with respect to the meridional SDT amplitudes in the $\mathrm{NH}$ mesosphere during two 120-day NH summer-fall seasons (days 181-300; 30 June-27 October, 2006 and 2007). A summer-fall interval is chosen because the PW activities for the SH occur most often during these months. The sequence of SDT amplitude is kept constant for each contour plot. Although the plots are shown in global latitudes, the correlations in the SH (the opposite hemisphere relative to the tides used) high-latitude stratosphere and lower mesosphere are primarily discussed. The $\mathrm{NH}$ results are not discussed due to little SPW activity in the NH for July-September. Since each time sequence is obtained over a window of 4 days that is stepped by 1 day, the successive data points are not independent, thus reducing the degrees of freedom. In this paper, a Monte-Carlo shuffling method (e.g. Ebisuzaki, 1997; Usoskin et al., 2006) is applied to estimate the significance of correlation. This spectral method ensures that the significances are appropriate to the degrees of freedom existing in each of the time sequences and hence correlations.

\subsection{SH SPW1 versus SDT at $\sim 80^{\circ} \mathrm{N}$}

Figure 1 shows the correlations between the meridional SDT amplitudes observed at Svalbard $\left(78^{\circ} \mathrm{N}, 16^{\circ} \mathrm{E}\right)$ and Eureka $\left(80^{\circ} \mathrm{N}, 86^{\circ} \mathrm{W}\right)$ with the SPW1 amplitudes throughout the global middle atmosphere for 30 June-27 October, 2006 and 2007. The top sections of Fig. 2 present the time sequences of $88 \mathrm{~km}$ and $94 \mathrm{~km}$ tidal amplitudes at Svalbard and Eureka compared with the SPW1 amplitudes at $10 \mathrm{hPa}, 60-65^{\circ} \mathrm{S}$ and at $10 \mathrm{hPa}, 55-60^{\circ} \mathrm{N}$ during season $2006 / 2007$.

The SPW1 amplitudes in the stratosphere at the SH high latitudes generally show weak positive correlations with the meridional SDT amplitude at $82 \mathrm{~km}$ observed at Svalbard during summer-fall of 2006 (Fig. 1a). Similar correlation patterns are found with respect to the tide at $88 \mathrm{~km}$, although the values are even weaker (Fig. 1b). Correspondingly, the Svalbard meridional SDT amplitude at $88 \mathrm{~km}$ attains a maximum in September, while the simultaneous SPW1 amplitude in the opposite hemisphere is not large (e.g. red versus black in Fig. 2a). This weakens the correlations between them and also indicates that this autumn intensification of the Svalbard SDT is not associated with the SH SPW1 activity. As opposite to the $82 \mathrm{~km}$ and $88 \mathrm{~km}$ tides, the Svalbard $94 \mathrm{~km}$ SDT amplitudes show strong negative correlations with the SPW1 amplitudes in the high-latitude southern stratosphere (Fig. 1c). However, notice that these negative correlations are statistical artifacts, caused by trends. Figure $2 \mathrm{c}$ indicates the opposite seasonal trends between the $94 \mathrm{~km}$ Svalbard SDT amplitudes and the SPW 1 amplitude at $10 \mathrm{hPa}, 60-65^{\circ} \mathrm{S}$ : the former is larger in July-September than in October (black in Fig. 2c) while the SPW1 is weaker in July-August than in September-October (red in Fig. 2c). In the case of the Eureka SDT amplitudes as the locationally fixed sequences, we do 

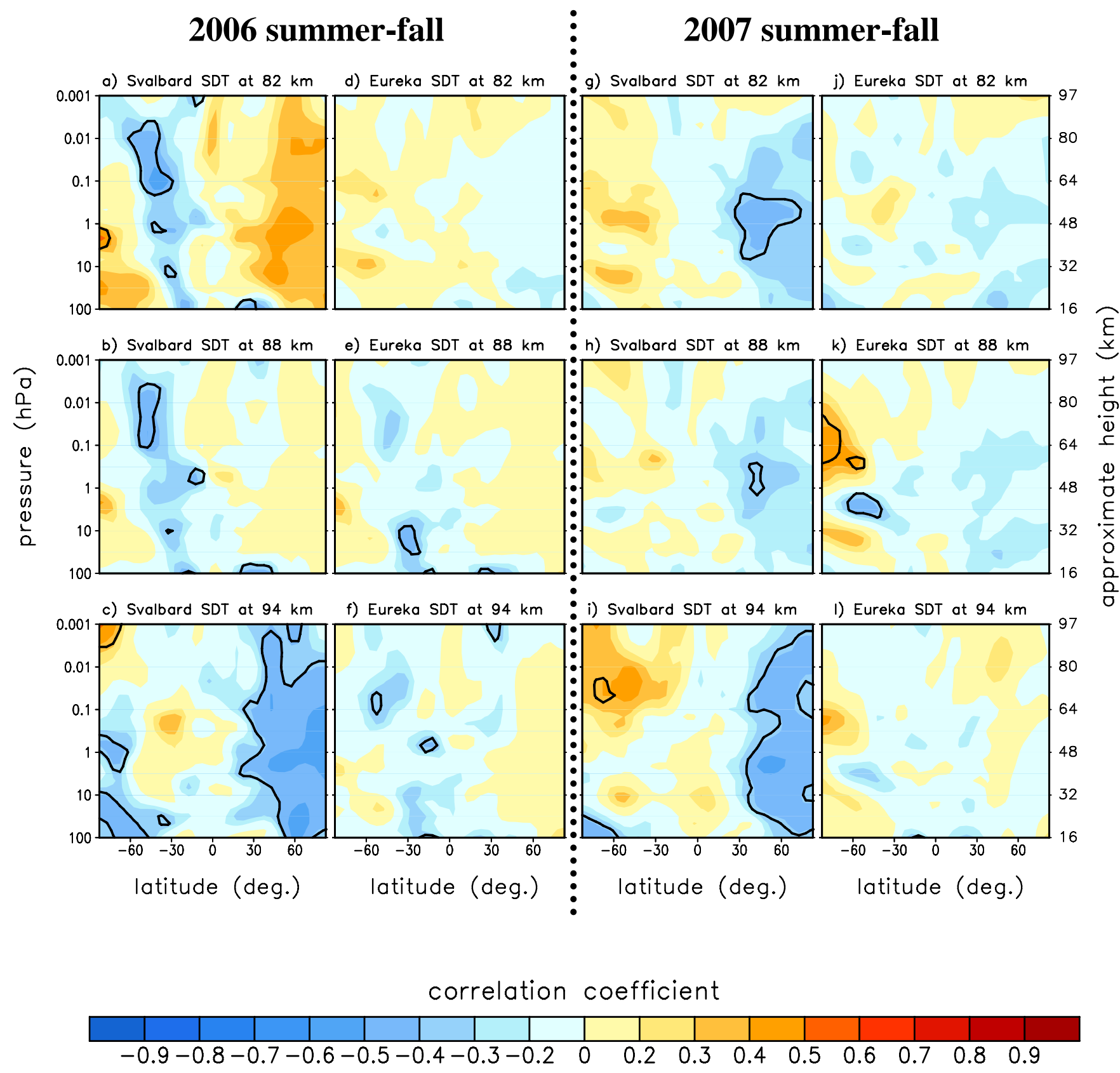

Fig. 1. Correlation coefficients between the stationary planetary wave 1 amplitude at each latitude/pressure with the amplitudes of meridional semidiurnal tides observed at Svalbard $\left(78^{\circ} \mathrm{N}, 16^{\circ} \mathrm{E}\right)$ and Eureka $\left(80^{\circ} \mathrm{N}, 86^{\circ} \mathrm{W}\right)$ for 30 June-27 October, 2006 and 2007. amplitude sequence is kept constant for each contour plot. From top to bottom the tidal heights are 82,88 and $94 \mathrm{~km}$. The black lines indicate a $95 \%$ level of significance.

not see their significant correlations with the SPW1 in high southern latitudes during this summer-fall (Figs. 1d-f). Little correspondence is found between the Eureka $88 \mathrm{~km}$ and $94 \mathrm{~km}$ SDT amplitudes and the SPW1 amplitudes at $10 \mathrm{hPa}$, $60-65^{\circ} \mathrm{S}$ (black vs. red in Fig. $2 \mathrm{~b}$ and d).

Based on the technique described in Sect. 2, time sequences of the percentage-power of the migrating SDT for the meridional component, as derived from the SvalbardEureka pair for season 2006/2007, are also shown in Fig. 2 (solid in sections e-g). It is shown that the migrating SDT dominates for the $94 \mathrm{~km}$ in June-July, and then almost exclusively for all 3 heights from August through January, except for the upper heights in October-November. The autumn (September) enhancement in the Svalbard and Eureka 

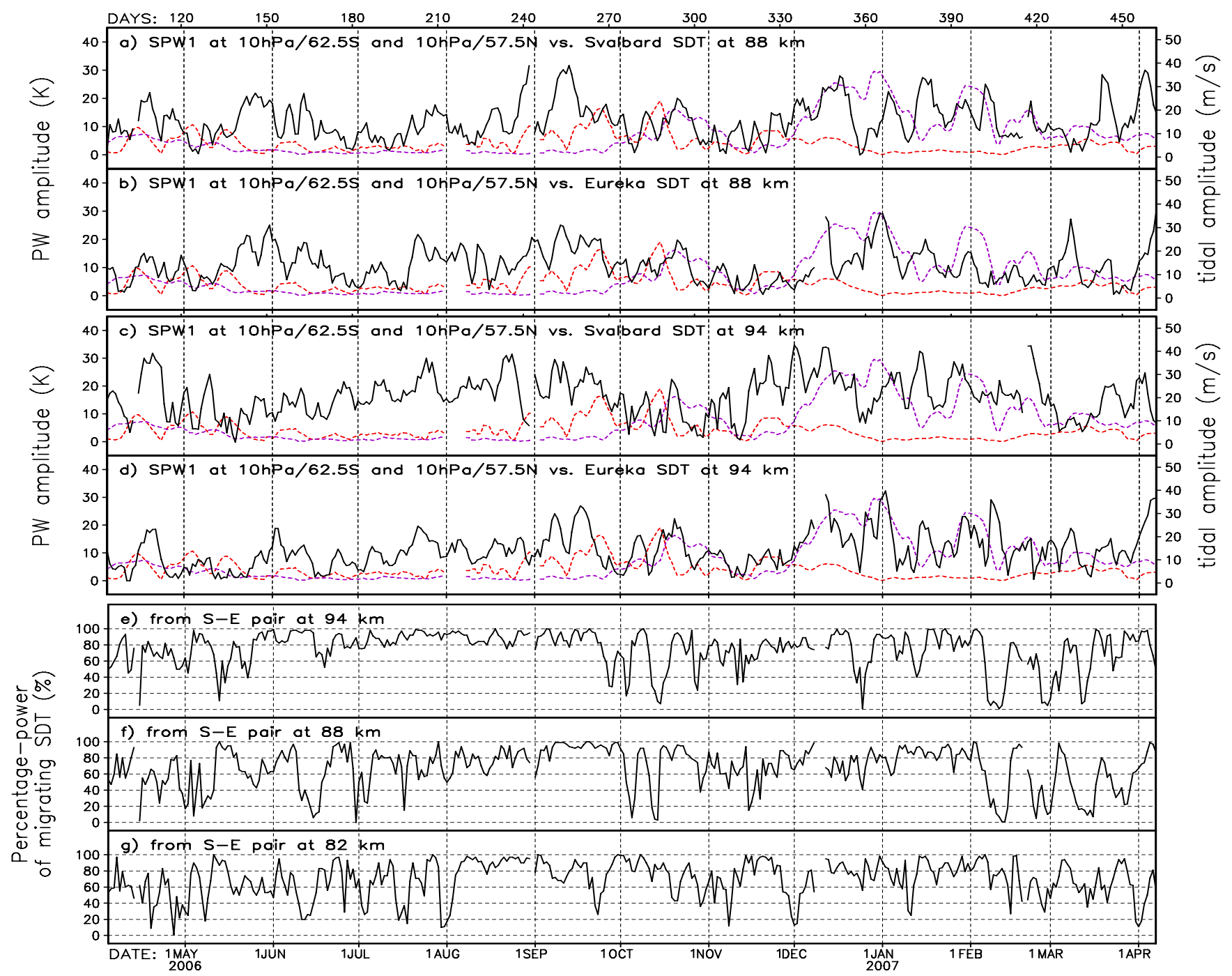

Fig. 2. Time sequences of the stationary planetary wave 1 amplitudes (dashed line; scale on left axis; shown in (a-d) at $10 \mathrm{hPa}, 60-65^{\circ} \mathrm{S}$ (red) and at $10 \mathrm{hPa}, 55-60^{\circ} \mathrm{N}$ (purple) versus the amplitudes of meridional semidiurnal tides (solid line; scale on right axis; showing in (a-d) at Svalbard (a for $88 \mathrm{~km}$ and c for $94 \mathrm{~km}$ ) and Eureka (b for $88 \mathrm{~km}$ and d for $94 \mathrm{~km}$ ) during 2006/2007. The percentage-power in the migrating SDT derived from the Svalbard-Eureka pair is shown in the lower sections of the figure (solid lines, e-g).

SDT amplitudes for $88 \mathrm{~km}$ is clearly a characteristic of the migrating SDT, with the power of MT values close to $100 \%$ (Fig. 2f). The presence of non-migrating SDT for the upper heights during the equinoctial time (October) is likely to be a result of the global forcing of NMT by the SPW (Manson et al., 2009) since the October SPW activities in both hemispheres are often comparable (e.g. red versus purple in Fig. 2).

Moving to the 2007 summer-fall, the stratospheric SPW1 amplitudes in the SH high latitudes do not provide positive correlations beyond $95 \%$ significance level with the Svalbard meridional SDT amplitudes (Fig. 1g-i). Similarly, the Eureka meridional SDT amplitude at $82 \mathrm{~km}$ is not correlated with the SH SPW1 amplitudes (Fig. 1j). The $88 \mathrm{~km}$ tide is shown to be positively correlated only with the SPW1 amplitudes in the lower mesosphere at high southern latitudes (Fig. 1k). Similar SH correlation patterns are found for the Eureka tide at $94 \mathrm{~km}$, although the correlations are further weakened (Fig. 11). The time sequences of the \% power of the migrating SDT (not shown for 2007/2008) also indicates that at $80^{\circ} \mathrm{N}$ the migrating SDT plays a more important role at most times for the 3 heights during 2007/2008.

Overall, during these two summer-fall seasons (Fig. 1), the mesospheric SDT amplitudes observed at the $\mathrm{NH}$ polar latitudes $\left(\sim 80^{\circ} \mathrm{N}\right)$ usually do not show persistent significant correlations with the SPW1 amplitudes in the high-latitude southern stratosphere. We also repeated the correlation calculations with variable lags between the time sequences of 


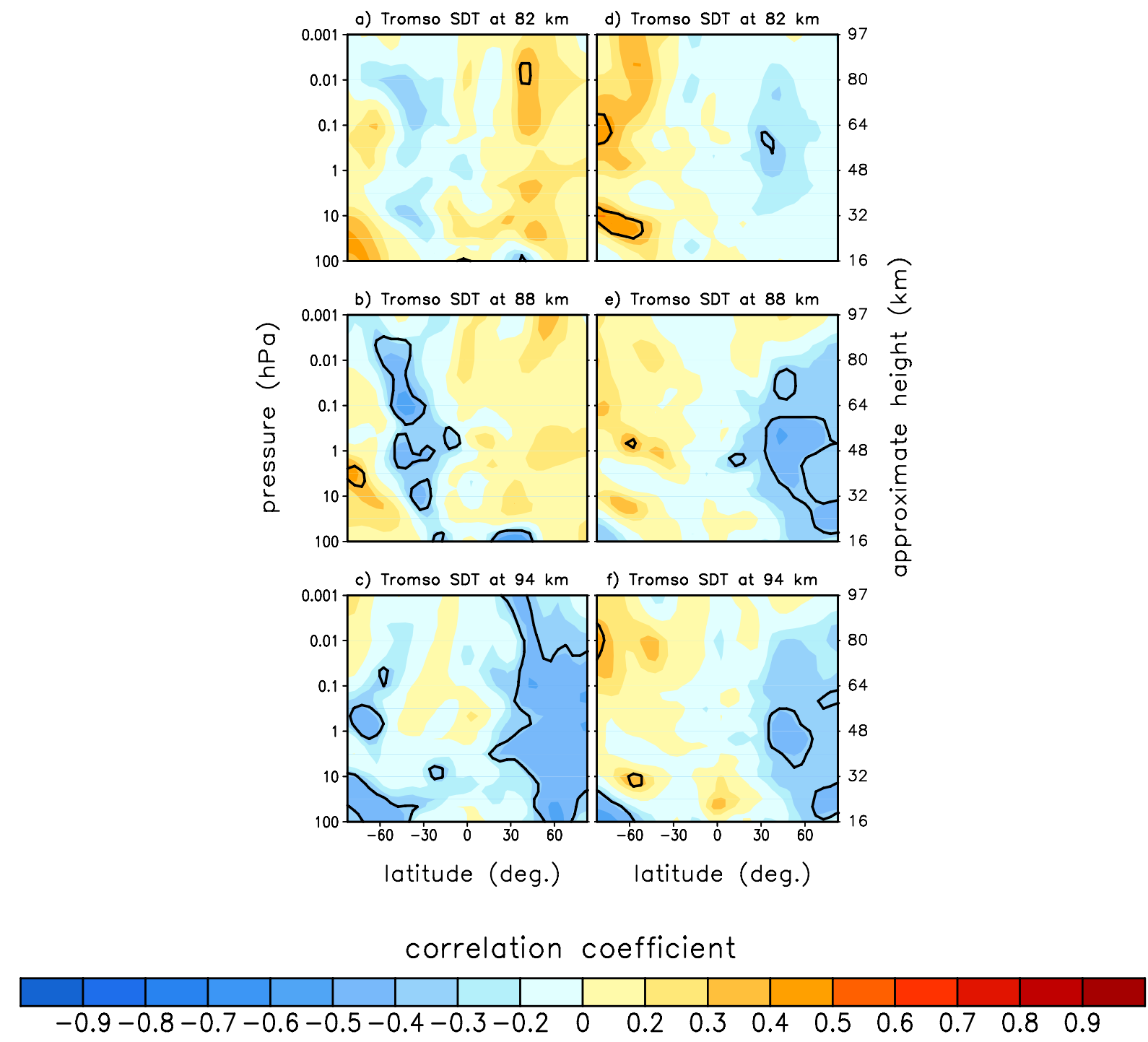

Fig. 3. Correlation coefficients between the stationary planetary wave 1 amplitude at each latitude/pressure with the meridional semidiurnal tide amplitudes observed at Troms $\emptyset\left(70^{\circ} \mathrm{N}, 19^{\circ} \mathrm{E}\right)$ for 30 June-27 October 2006 (left column) and for 30 June-27 October 2007 (right column). Otherwise details are as in Fig. 1.

the tidal and SPW1 amplitudes, but do not find clear lagvalues.

\subsection{SH SPW1 versus SDT at $\sim 7^{\circ} \mathrm{N}$}

This subsection looks at the relationships of the SH SPW1 amplitudes in the middle atmosphere with the mesospheric meridional SDT amplitudes measured at Troms $\varnothing\left(70^{\circ} \mathrm{N}\right.$, $19^{\circ} \mathrm{E}$ ) during the 2006 and 2007 summer-falls. At the latitudes of $\sim 70^{\circ} \mathrm{N}$, there are currently no suitable/continuous mesospheric wind observations available in the PacificCanada longitudinal sector. So the relative importance of migrating and non-migrating tides cannot be directly analysed for this latitude band. Further, the existence of significant correlations, positive or negative, will depend not only upon the existence of NMT during the intervals assessed, but also whether Troms $\varnothing$ lies (by chance) within the longitudes where the MT and the NMT interfere constructively or destructively (Sect. 6, Discussion).

Figure 3 shows the correlation for the SPW1 amplitude with respect to the Troms $\varnothing$ NS SDT amplitude as a function of global latitude and height for two 120-day summer-fall seasons (30 June-27 October, 2006 and 2007). The correlations for the SPW1 amplitudes with the Troms $\varnothing$ tidal amplitude (Fig. 3a-c) are similar to those with the Svalbard tide (Fig. 1a-c) during the 2006 summer-fall. Although significant positive correlations are indicated between the SPW1 amplitudes in a small height range $(\sim 5 \mathrm{~km})$ of the polar latitude southern stratosphere and the Troms $\varnothing$ tidal amplitude at 

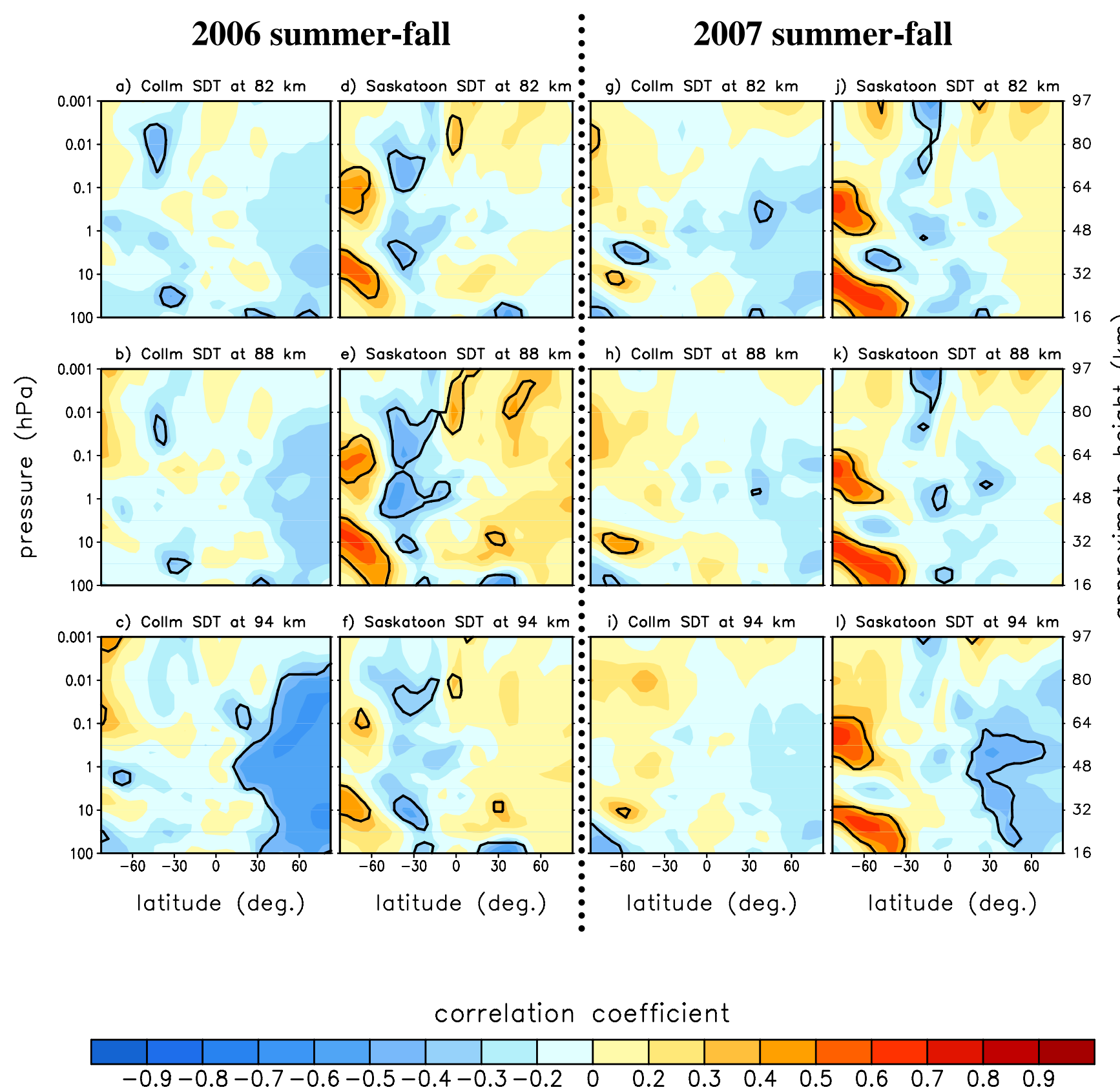

Fig. 4. Correlation coefficients between the stationary planetary wave 1 amplitude at each latitude/pressure with the amplitudes of meridional semidiurnal tides observed at Collm $\left(51^{\circ} \mathrm{N}, 13^{\circ} \mathrm{E}\right)$ and Saskatoon $\left(52^{\circ} \mathrm{N}, 253^{\circ} \mathrm{E}\right)$ for 30 June-27 October, 2006 and 2007. Otherwise details $^{\circ}$ are as in Fig. 1.

$88 \mathrm{~km}$ (Fig. 3b), the non-migrating contribution to the variability of the latter is expected to be not substantial during this period based upon extrapolation from the analyses at $\sim 80^{\circ} \mathrm{N}$ (Fig. 2f).

During the 2007 summer-fall months, the SPW1 amplitude fluctuations in high latitude southern stratosphere and lower mesosphere are well correlated with the Troms $\varnothing$ tidal amplitude at $82 \mathrm{~km}$ (Fig. 3d). The correlations are weak- ened with respect to the tidal amplitudes at the upper heights (Fig. 3e and f). Similar characteristics are found by Smith et al. (2007) between the SABER SPW1 in the SH and the Esrange $\left(68^{\circ} \mathrm{N}, 21^{\circ} \mathrm{E}\right) \mathrm{SDT}$ amplitudes for 2002-2005. However, note that the impact of the non-migrating tide on the Troms $\varnothing$ tidal variability is expected to be smaller than that of the migrating tide during this interval, by the extrapolation based on the $\%$ power of MT analyses at $\sim 80^{\circ} \mathrm{N}$ and 


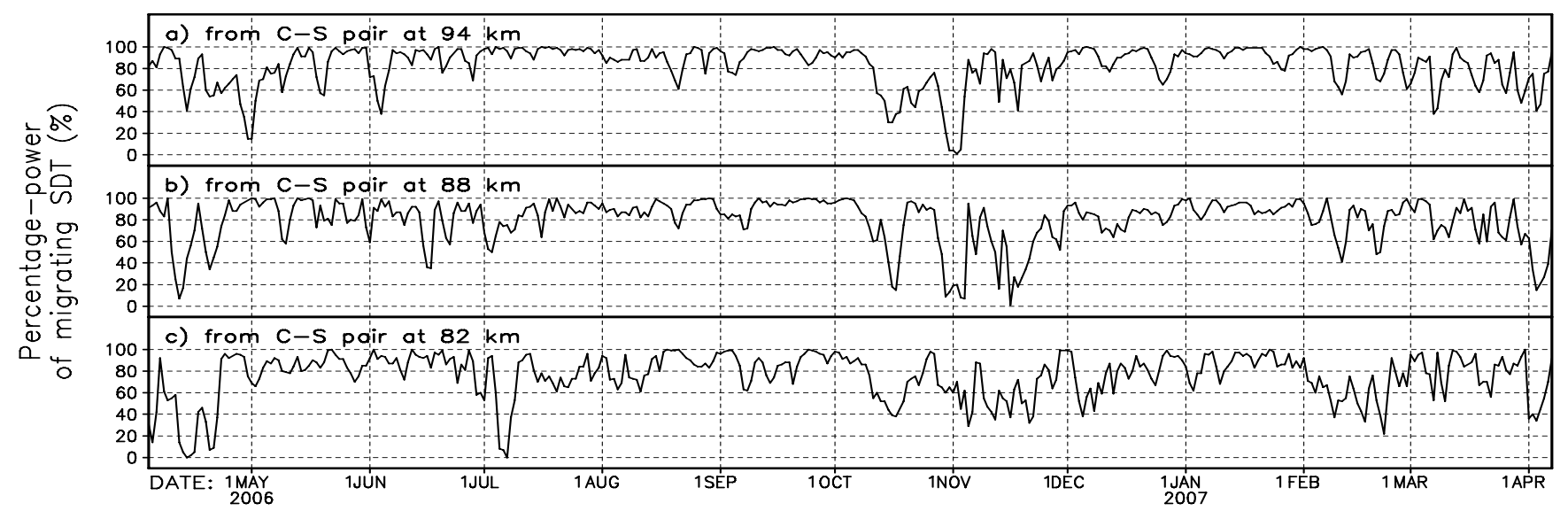

Fig. 5. Time sequences of the percentage-power in the migrating SDT derived from the Collm-Saskatoon pair during $2006 / 2007$.

discussions in Manson et al. (2009). In addition, Portnyagin et al. (2004) also argued that the migrating tides (diurnal and semidiurnal) are dominant in the southern Arctic $\left(65-75^{\circ} \mathrm{N}\right)$ during all months except for May and June. Examination of time sequences (not shown here) reveals that the correlation is provided mainly by the variability over time-scales of $\sim 30$ days or more.

\subsection{SH SPW1 versus SDT at $\sim 50^{\circ} \mathrm{N}$}

In this subsection, the mesospheric NS SDT amplitudes measured by the Collm $\left(51^{\circ} \mathrm{N}, 13^{\circ} \mathrm{E}\right) \mathrm{MWR}$ and Saskatoon $\left(52^{\circ} \mathrm{N}, 253^{\circ} \mathrm{E}\right) \mathrm{MFR}$ are chosen to be correlated with the global SPW1 amplitudes in the stratosphere and mesosphere. Figure 4 displays the correlations respectively for the two summer-fall intervals.

We do not see significant and positive correlations between the Collm meridional SDT amplitude and stratospheric SPW1 amplitudes in high southern latitudes during the 2006 summer-fall for the 3 tidal heights (Fig. 4a-c). In contrast, the meridional SDT amplitudes observed at Saskatoon seem to be well correlated with the SPW1 amplitudes in high latitude southern stratosphere and lower mesosphere during the 2006 summer-fall interval (Fig. 4d-f). Two maxima of correlation are clearly observed in high southern latitudes with one between $100-2 \mathrm{hPa}$ and the other around $0.1 \mathrm{hPa}$. These high correlations are due to the general agreement between long-term variations of the two variables, including strong trends during the months of SeptemberOctober. We have also calculated lagged correlation coefficient between the two variables (not shown) and find that these strong positive correlations in the SH high latitudes always exist for time-lags ranging from $\sim+10$ to -10 days. This also indicates that these correlations are dominated by the low frequency variability in the sequences.

Like the Svalbard-Eureka pair, the Collm MWRSaskatoon MFR pair also allows us to estimate the relative importance of the MT/NMT. The wind speed-bias between MFR and MWR varies with height and season, smaller for lower mesospheric heights and summer and larger for upper mesospheric altitudes and winter (Manson et al., 2004c; Hall et al., 2005; Jacobi et al., 2009). So for the upper mesosphere and winter, the bias could produce artificial NMT. To reduce the effect of the MFR/MWR bias, the Collm-MWR winds at $94 \mathrm{~km}$ are multiplied by a factor of $0.5(0.8)$ for the winter (summer) months; the MWR winds at $88 \mathrm{~km}$ are multiplied by a factor of 0.8 for the winter months. The ratio values are derived from the study of Jacobi (2009) that compared Collm MWR with Juliusruh $\left(55^{\circ} \mathrm{N}, 13^{\circ} \mathrm{E}\right)$ MFR winds. Figure 5 provides the time sequences of the percentage-power of migrating NS SDT that are determined from the Collm-Saskatoon pair for season 2006/2007. At $51 / 52^{\circ} \mathrm{N}$, the dominance of the MT occurred nearly throughout the whole season 2006/2007 for the 3 heights (Fig. 5ac), except for October-November. The late-summer/earlyautumn enhancement in the SDT amplitude is predominately a characteristic of the migrating tide.

For the 2007 summer-fall, the Collm tidal amplitudes are shown to be positively correlated with the SPW1 around $10 \mathrm{hPa}, 65^{\circ} \mathrm{S}$ (Fig. 4g-i). These positive correlations are strongest in the case of the $88 \mathrm{~km}$ tidal height (Fig. 4h). Figure 6 presents the time sequences of the $88 \mathrm{~km}$ SDT amplitudes observed at Collm and Saskatoon, along with the SPW1 amplitudes at $10 \mathrm{hPa}, 65-70^{\circ} \mathrm{S}$ and at $31.6 \mathrm{hPa}, 50-$ $55^{\circ} \mathrm{N}$ during 2007/2008. We can see that the Collm $88 \mathrm{~km}$ tidal amplitude varies in correlation with the SPW1 amplitude at $10 \mathrm{hPa}, 65-70^{\circ} \mathrm{S}$ on monthly time scales from midJuly to mid-October (black vs. red in Fig. 6a). However, notice that the Collm tides are also relatively large and variable in June and July, when the global SPW1 amplitudes and variability are quite minimal. Similar to during the 2006 summer-fall, the Saskatoon NS SDT amplitudes at the 3 heights are all shown to be significantly and positively correlated with the SPW1 amplitudes between $100-3 \mathrm{hPa}$ 


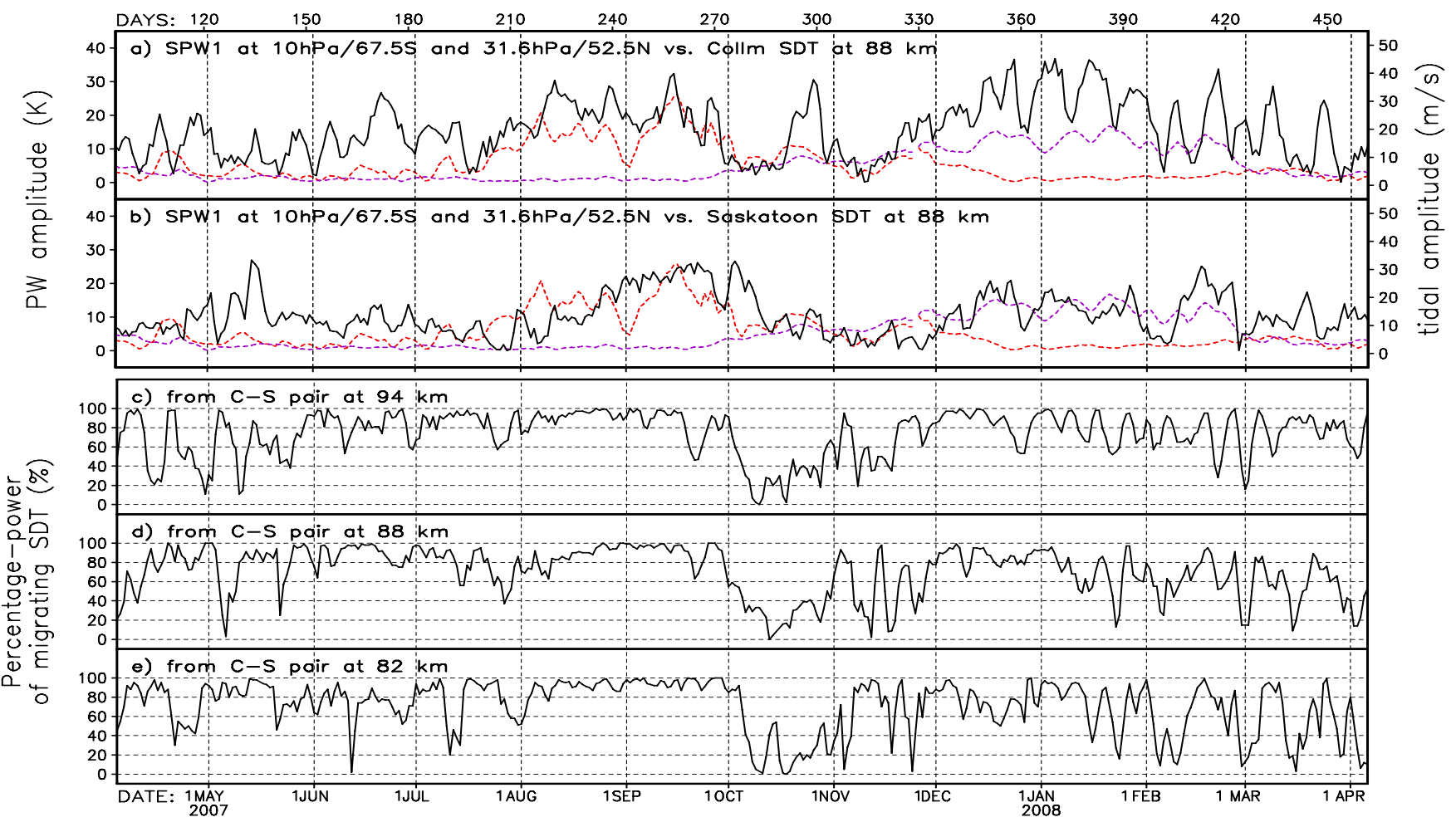

Fig. 6. Time sequences of the stationary planetary wave 1 amplitudes (dashed line; scale on left axis; shown in a and b) at $10 \mathrm{hPa}, 65-70^{\circ} \mathrm{S}$ (red) and at $32 \mathrm{hPa}, 50-55^{\circ} \mathrm{N}$ (purple) versus the amplitudes of $88 \mathrm{~km}$ meridional semidiurnal tides (solid line; scale on right axis; showing in a and b) observed at Collm (a) and Saskatoon (b) during 2007/2008. The percentage-power in the migrating SDT derived from the Collm-Saskatoon pair is shown in the lower sections (solid lines, $\mathbf{c - e}$ ).

and between $1-0.1 \mathrm{hPa}$, in high southern latitudes during the 2007 summer-fall (Fig. 4j-1). These correlations are dominated by the similarity between the long term (monthly timescales) variations for the amplitudes of the tides and $\mathrm{SH}$ SPW1 (e.g. black vs. red in Fig. 6b). Hence, these correlations also occur over a wide range of time-lags (not shown). Time sequences of the percentage-power of the migrating SDT, as obtained from the Collm-Saskatoon pair for season 2007/2008, are also shown in Fig. 6. Apparently, in the $\mathrm{NH}$ high mid-latitudes $\left(\sim 50^{\circ} \mathrm{N}\right)$, the migrating $(\mathrm{s}=2)$ SDT dominates during all summer-autumn months for the 3 MLT heights. The exception is the relative dominance of the nonmigrating SDT in October 2007. The MT is usually much stronger or dominant $(100 \%)$ over the NMT during AugustSeptember when both the Collm and Saskatoon SDT amplitudes are large. Note that in October 2007 the SPW activities in both hemispheres (e.g. red and purple in Fig. 6) are probably responsible for what we claim to be the dominance of the NMT by the global forcing, although this has a weak effect on the 120-day correlation between the observed SDT and the SH SPW1.

Notice that strong correlations (positive and negative) appearing in the $\mathrm{NH}$ in Figs. 1, 3 and 4 apparently have no physical meaning: they are statistical artefacts caused by the trends relative to the NH SPW1 transition from the early autumn into the early winter (e.g. purple in Figs. 2 and 6), and the characteristic late summer/early autumn variability of the tides, the latter associated with seasonal/altitudinal changes in tidal Hough-mode composition of the MT (Riggin et al., 2003; Manson et al., 2006).

\section{Correlation analyses between the NH SPW1 and NH SDT amplitudes during NH winter}

This section presents the correlation analyses similar to those in Sect. 3, but for two 120-day NH winters (days 311-430; 7 November-6 March 2006/2007 and 7 November-5 March 2007/2008). Here the NH (the local hemisphere relative to the tides used) results are primarily discussed since the SPW activities are mainly confined to the $\mathrm{NH}$ during $\mathrm{NH}$ winter months (Manson et al., 2009).

Figure 7 shows the correlations between the NS SDT amplitudes at $\sim 80^{\circ} \mathrm{N}$ and SPW1 amplitudes throughout the global middle atmosphere for winters 2006/2007 and 2007/2008 (days 311-430). For the Svalbard tide at $82 \mathrm{~km}$, positive correlations are found in the lower stratosphere in the NH mid-high latitudes $\left(\sim 50-70^{\circ} \mathrm{N}\right)$ for the $2006 / 2007$ winter (Fig. 7a). These correlations are gradually weakened 


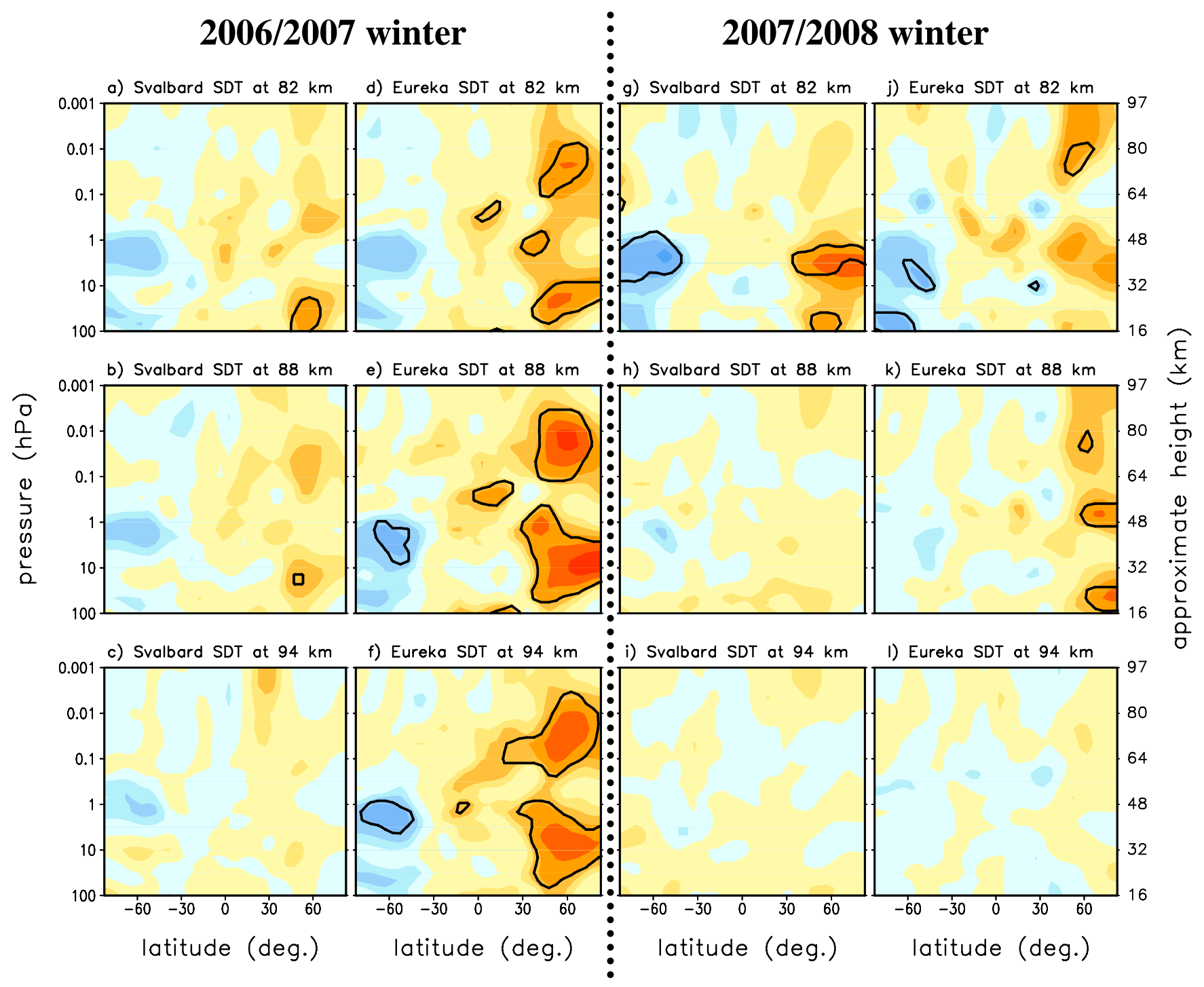

Fig. 7. Correlation coefficients between the stationary planetary wave 1 amplitude at each latitude/pressure with the amplitudes of meridional semidiurnal tides observed at Svalbard and Eureka for 7 November-6 March, 2006/2007 and for 7 November-5 March 2007/2008. Otherwise details are as in Fig. 1.

as the tidal height is increased (Fig. $7 \mathrm{~b}$ and c). During this winter, the amplitudes of the NS SDT observed at Eureka are found to be highly and positively correlation with the SPW1 amplitudes in the local mid-high latitudes (Fig. 7df). Two correlation maxima are respectively observed in the local stratosphere and in the local mesosphere for each tidal height. The strongest are found for the tidal height of $88 \mathrm{~km}$ (Fig. 7e). Comparison of time-sequences illustrates that the variations of the Eureka $88 \mathrm{~km}$ tidal amplitude and the SPW1 amplitude in the local stratosphere show a good consistency on time scales of approximately $>15$ days during October-February of 2006/2007 (e.g. black vs. purple in Fig. 2b). During the second winter, the Svalbard meridional SDT amplitude at $82 \mathrm{~km}$ is also found to be significantly and positively correlated with the SPW1 amplitudes in the high latitude local stratosphere (Fig. 7g), although these correlations are not seen for the upper tidal heights (Fig. $7 \mathrm{~h}$ and i). We also see significant positive correlations between the Eureka NS SDT amplitude at $88 \mathrm{~km}$ and the SPW1 amplitudes in the local hemisphere's polar latitudes for this winter interval (Fig. 7k). However, these correlations are weakened for the Eureka tides at $82 \mathrm{~km}$ and $94 \mathrm{~km}$ (Fig. $7 \mathrm{j}$ and l).

Moving to somewhat lower latitudes, Fig. 8 presents the correlations between the Troms $\varnothing\left(70^{\circ} \mathrm{N}\right)$ NS SDT amplitudes and SPW1 amplitudes throughout the global stratosphere and mesosphere for winters 2006/2007 and 2007/2008. During the first winter, significant positive correlations are found throughout the middle atmosphere in the 

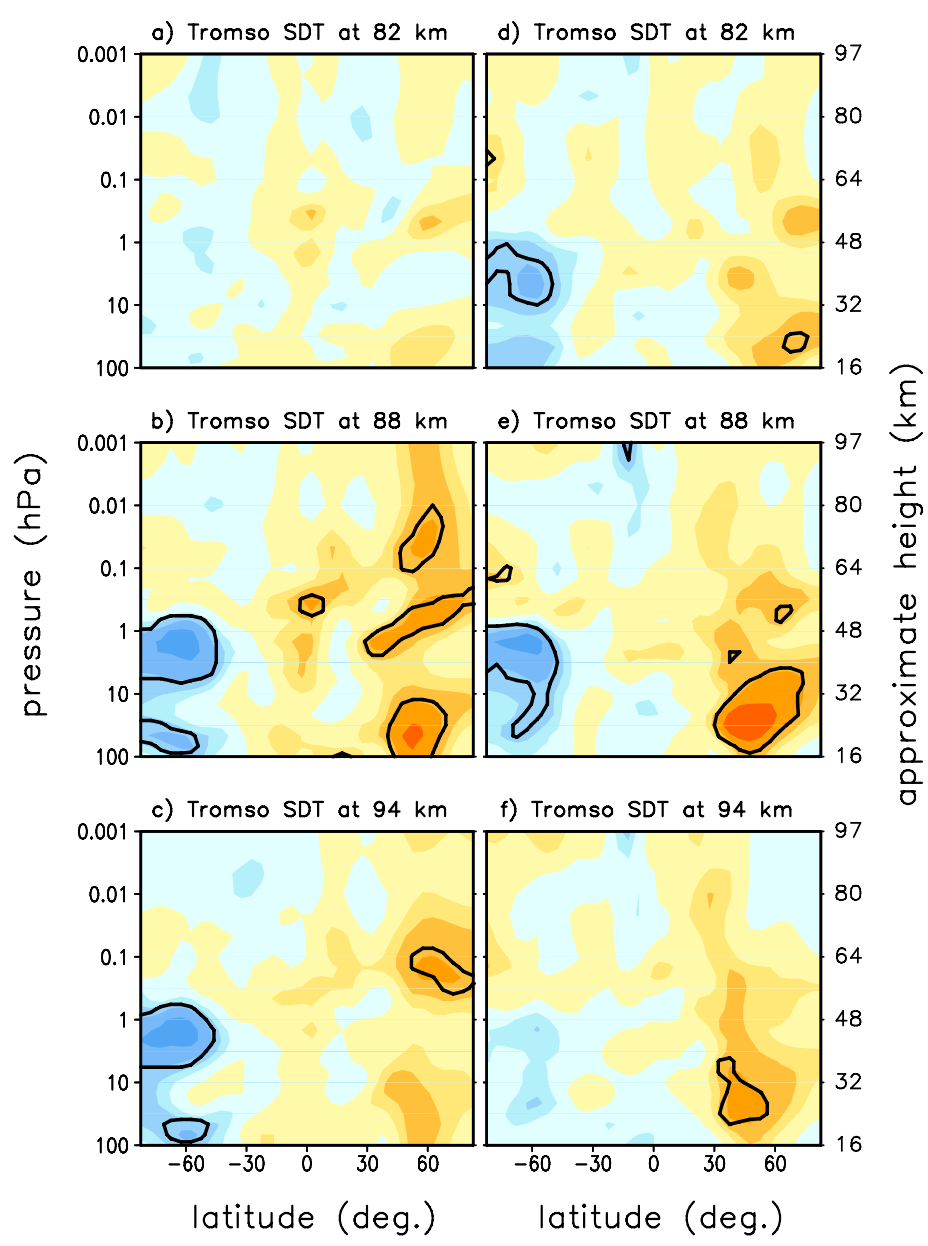

correlation coefficient

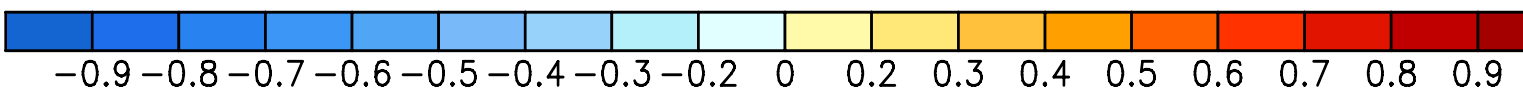

Fig. 8. Correlation coefficients between the stationary planetary wave 1 amplitude at each latitude/pressure with the meridional semidiurnal tide amplitudes observed at Troms $\emptyset$ for 7 November-6 March 2006/2007 (left column) and for 7 November-5 March 2007/2008 (right column). Otherwise details are as in Fig. 3.

local mid-high latitudes $\left(\sim 45-75^{\circ} \mathrm{N}\right)$ with respect to the tide at $88 \mathrm{~km}$ (Fig. $8 \mathrm{~b}$ ). These correlations are attributed largely to the similar monthly-scale oscillations of two variables (not shown here). The correlations are weakened for the tides at $82 \mathrm{~km}$ and $94 \mathrm{~km}$ (Fig. $8 \mathrm{a}$ and c). Similar characteristics are found for the 2007/2008 winter, although the strong positive correlations more often occur in the local lower stratosphere (Fig. 8d-f).

For the high mid-latitudes $\left(51 / 52^{\circ} \mathrm{N}\right)$, the mesospheric SDT amplitudes observed at Collm and Saskatoon are often found to be positively and strongly correlated with the stratospheric SPW1 amplitudes at similar latitudes (i.e. below the tidal observations) during winter months (not shown). These correlations are also usually related to the agreement on monthly-scale variations of the two variables (e.g. black vs. purple in Fig. 6a and b).

Note that strong negative correlations occurring in the SH of Figs. 7 and 8 are statistical artefacts which are caused by the trend relative to the SH SPW1 transition from the final spring warming into the summer (e.g. red in Figs. 2 and 6), and the characteristic variability of the tides, the latter again associated with seasonal/altitudinal changes in tidal Houghmode composition (Manson et al., 2006, 2009).

\section{Cross-spectral analysis}

As noted above, the correlations obtained in Sects. 3 and 4 are often dominated by the low frequency variability based 

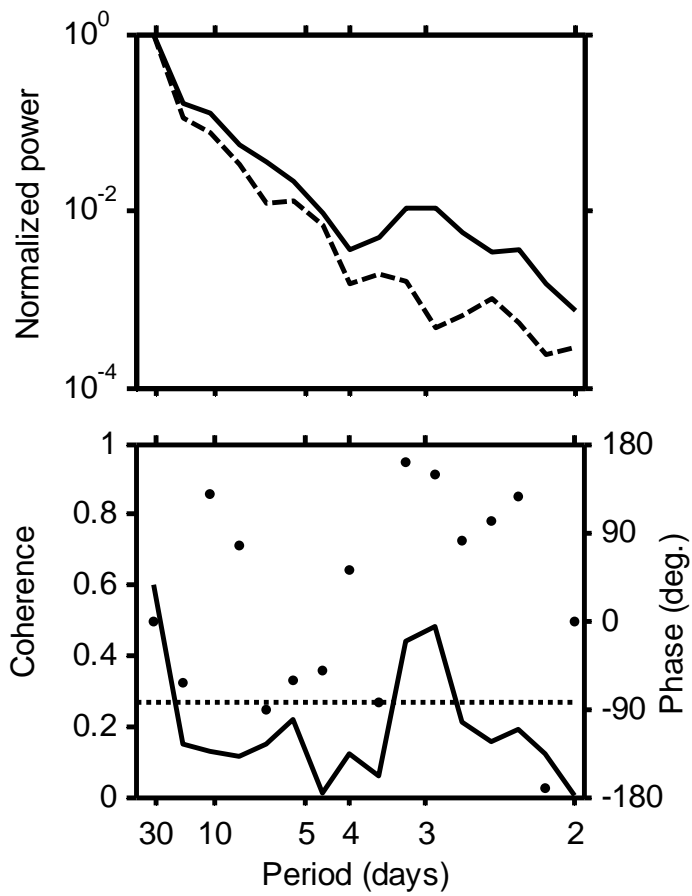

Fig. 9. Spectral analysis for time sequences of the stationary planetary wave 1 amplitude at $10 \mathrm{hPa}, 65-70^{\circ} \mathrm{S}$ and the Saskatoon meridional semidiurnal tide amplitude at $88 \mathrm{~km}$ during the 120 -day summer-fall interval of 2007. The two time sequences are shown with red and black lines in Fig. $6 \mathrm{~b}$ and the correlation coefficient between them is 0.74 (as included in Fig. 4k). Upper panel: the normalized power (dashed for the planetary wave amplitude sequence, solid for the tidal amplitude sequence). Lower panel: coherence (solid, scale on left axis) and phase (dots, scale on right axis) between the two time sequences as a function of period. The dashed line in the lower panel indicates a $95 \%$ confidence level. See text for details.

on the examination of time sequences. Further, a crossspectral analysis can determine the correlation coefficient as a function of the frequency which cannot be seen in the integrated analysis. Here two examples are chosen for such spectral analyses.

In Fig. 9, the 120 days of data for the SPW1 amplitude at $10 \mathrm{hPa}, 65-70^{\circ} \mathrm{S}$ and amplitude of the Saskatoon NS SDT at $88 \mathrm{~km}$ during the 2007 summer-fall (days 181-300), have been used. The two time sequences are shown with red and black lines in Fig. $6 \mathrm{~b}$ and the correlation coefficient between them is 0.74 as included in Fig. 4k. The upper panel of Fig. 9 presents the normalized power spectra for the two time sequences, and the lower panel shows the coherence and phase between them as a function of period. These spectral estimates are obtained by direct Fourier transform. Block averaging has been used to improve the statistical reliability of these spectral estimates and introduce spectral noise for the coherence calculation. The time-sequences are partitioned into 7 segments with $50 \%$ overlap between the segments.

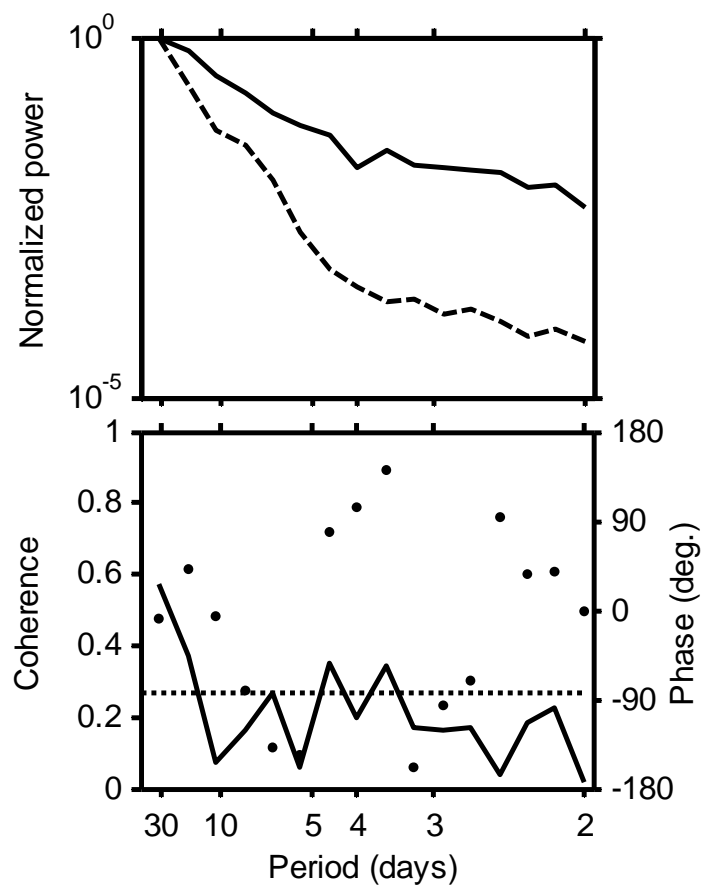

Fig. 10. Spectral analysis for time sequences of the stationary planetary wave 1 amplitude at $10 \mathrm{hPa}, 55-60^{\circ} \mathrm{N}$ and the Eureka meridional semidiurnal tide amplitude at $88 \mathrm{~km}$ during the 120 -day winter interval of 2006/2007. The two time sequences are shown with purple and black lines in Fig. $2 \mathrm{~b}$ and the correlation coefficient between them is 0.66 (as included in Fig. 7e). Otherwise details are as in Fig. 9.

Each segment is tapered with a Hanning window. Spectra are then calculated for each segment at each frequency band, and then are block averaged to form the final spectral estimates. For this example, the two power spectra show a clear characteristic of a "red" spectrum with a similar slope. Most of the energies occur at periods longer than 25 days. The maximum coherence appears at the lowest frequencies and the corresponding phase is close to $0 \mathrm{deg}$, indicating that the correlation between them is clearly dominated by the low frequency fluctuations ( $>25$ days). In addition, there is a clear anti-phase relation between them at periods around 3 days, which is a negative contribution to the positive correlation.

We next choose two 120-day time sequences that lead to a high correlation for the winter time. Figure 10 shows the same spectral analyses as Fig. 9, but for the SPW1 amplitude at $10 \mathrm{hPa}, 55-60^{\circ} \mathrm{N}$ and the Eureka NS SDT amplitude at $88 \mathrm{~km}$ during the 2006/2007 winter (days 311-430). The two time sequences are shown with purple and black lines in Fig. 2b. They also lead to a high correlation coefficient $(\sim 0.66)$ as included in Fig. 7e. In this case, the two power spectra also show a clear "red" behaviour, but the slope of the spectrum for the tidal amplitude is "flatter" than for the SPW1 amplitude. The latter illustrates that the high frequency variability plays a more important role for the tidal 


\section{CMAM-DAS: $88 \mathrm{Km}$ Merid. Semi-Diurnal Tide vs. Latitude and Wavenumber}

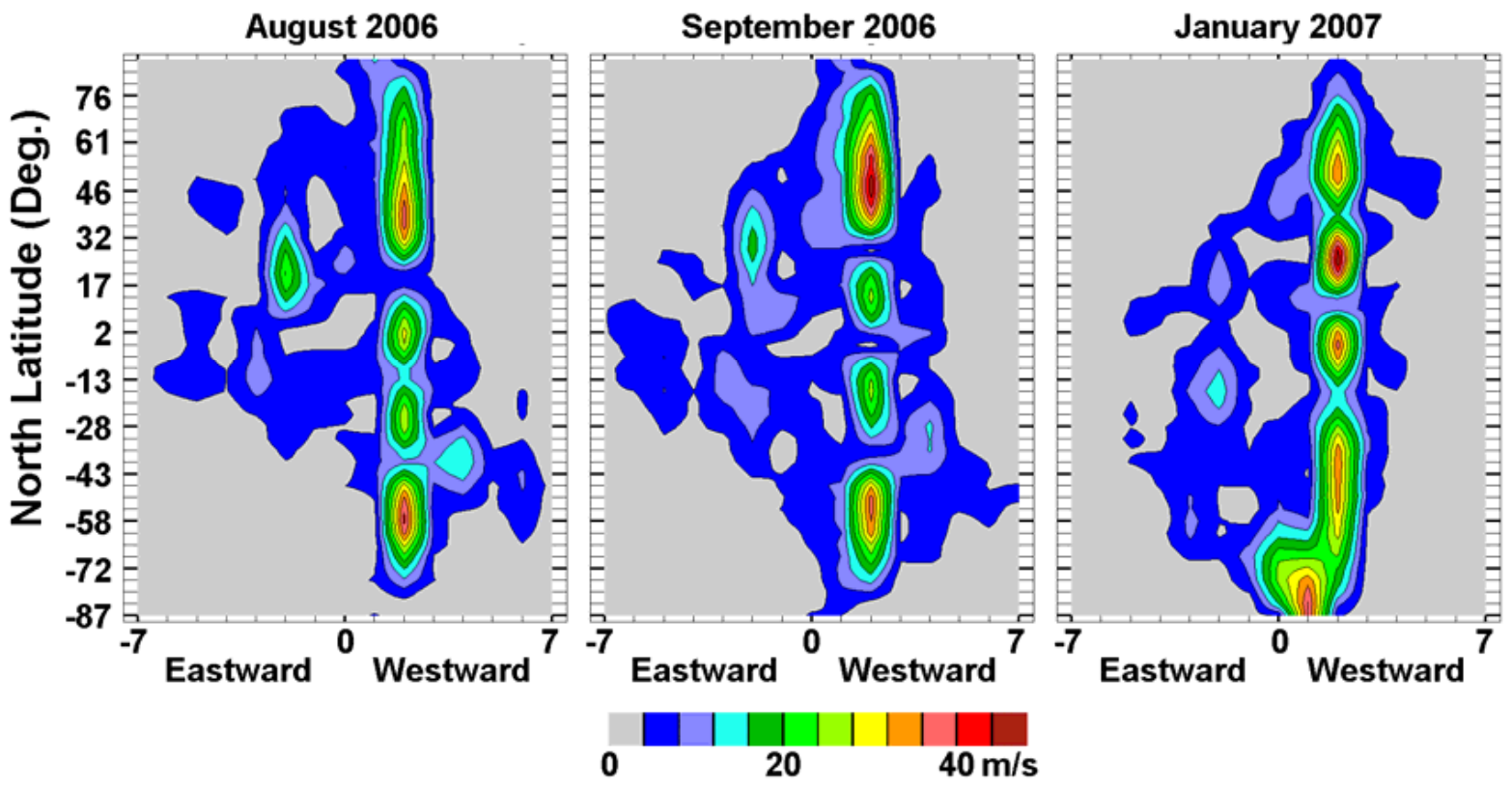

Fig. 11. Spatial spectral analysis from the CMAM-DAS (Canadian Middle Atmosphere Model with Data Assimilation System) for the meridional semidiurnal wind at $88 \mathrm{~km}$ and for three months (August, September 2006 and January 2007), providing wave number versus latitude contours of amplitude. Positive (negative) numbers represent westward (eastward) propagation.

amplitude than for the SPW1 amplitude. Also the maximum coherences are observed at long periods, illustrating that the correlation in this case is also contributed largely by the low frequency fluctuations ( $>15$ days).

\section{Discussion}

The SDTs used for comparisons in this study are observations made at single stations, which are the sums of all zonal wavenumber components including migrating and non-migrating tides. The extraction and use of zonal wavenumber components would clearly be of advantage (e.g. Baumgaertner et al., 2006; Murphy et al., 2009). While we are confident in the realism of the NMT-estimates from the use of radars at Eureka and Svalbard, which indicate the dominance of forcing at the SPW1 (Manson et al., 2009), at lower latitudes near $50^{\circ}$ there are likely to be other or multiple NMT wave numbers present (Manson et al., 2004a, b, 2006). For example forcing at wave number $S=4$ is significant there. Thus in this paper we have used the \% ratio of MT to the semidiurnal tidal variance observed at two locations.

Satellites, models or very extensive ground-based measurements are required to resolve all dominant wave numbers at tropical to polar latitudes (e.g. Manson et al., 2004a; Forbes and Wu, 2006; Cierpik et al., 2003; Angelats i Coll and Forbes, 2002; Jacobi et al., 1999; Oberheide et al., 2007). Specifically in this study, the relative contribution of migrating tide to the observed (wave number unresolved)
SDTs at polar latitudes $\left(\sim 80^{\circ} \mathrm{N}\right)$ and at high mid-latitudes $\left(\sim 50^{\circ} \mathrm{N}\right)$ are estimated based upon the observations from the Svalbard-Eureka pair and the Collm-Saskatoon pair. At the latitudes of Svalbard and Eureka and for the meridional component, the $s=2$ (migrating) SDT is often dominant in late summer time (July-September), while the non-migrating tide occurs typically during late fall (starting at upper heights in October and then onto December), late spring (April to June), and spasmodically during the winter (associated with stratospheric warmings). The favoured NMT wavenumber for 2006/2007 during such intervals was shown by Manson et al. (2009) to be $s=1$, for zonal and meridional components, after full discussion of the limitations of the use of pairs of radars for this purpose (also recall the discussion of wavenumber in Sect. 2 above). At the latitudes of Collm and Saskatoon, the MT dominates during nearly all months except for the October. The relative importance of MT/NMT is not directly analysed for the latitude of $70^{\circ} \mathrm{N}$ since there are currently no suitable mesospheric wind observations available in the Pacific-Canada longitudinal sector at this latitude. However, the non-migrating contribution to the Troms $\varnothing$ SDT variability is expected to be less important in late summer-early fall based upon the extrapolation from the analyses at $\sim 80^{\circ} \mathrm{N}$ and $\sim 50^{\circ} \mathrm{N}$. In addition, the studies of Manson et al. (2006) and Riggin et al. (2003) indicated that the migrating SDT is dominant during the mid-high latitudes $\left(40-65^{\circ} \mathrm{N}\right)$ maxima of August-September; and Portnyagin et al. (2004) also indicated that the migrating SDT dominates 
at $\sim 70^{\circ} \mathrm{N}$ during all months except for early summer. Figure 11 shows the wavenumber spectra based on the CMAMDAS (Canadian Middle Atmosphere Model with Data Assimilation System; Polavarapu et al., 2005) for the meridional SDT at $88 \mathrm{~km}$ and for three months (August, September 2006 and January 2007). In the NH the migrating SDT ( $\mathrm{s}=+2$, westward) is clearly dominant in late-summer/early fall (August-September) and mid-winter. The CMAM-DAS provides agreement with our fitting of the MT to the data from two radars, and then the determination of the relative importance of the MT/NMT.

During the two summer-fall seasons, the Troms $\varnothing$ SDT amplitudes below $90 \mathrm{~km}$ show significant and positive correlations with the SPW1 amplitudes in high latitude southern stratosphere and lower mesosphere (Fig. 3b and d), albeit for small height ranges. Positive correlations are even more evident for the tidal amplitudes observed at $\sim 50^{\circ} \mathrm{N}$. In particular, the Saskatoon SDT amplitudes are observed to be highly and positively correlated with the SPW1 amplitudes in high southern latitudes (Fig. 4). However, our explanation for the correlations differs from the study of Smith et al. (2007). As hypothesized by Smith et al. (2007), the NH summer-fall correlation between the amplitudes of the Esrange $\left(68^{\circ} \mathrm{N}\right) \mathrm{SDT}$ and SH SPW1 indicated a physical inter-hemispheric link; the dominance of the non-migrating contribution to the observed tidal variability could explain the correlation. However, the authors did not provide convincing evidence for the dominance of the non-migrating SDT at the latitude of Esrange. Here our analyses indicate the non-migrating SDT generally plays a much less important role than the migrating SDT at mid-high northern latitudes $\left(\sim 50-70^{\circ} \mathrm{N}\right)$ during late summer-early fall. Hence, the nonlinear interaction between the migrating SDT and the SH SPW, via the generations of non-migrating SDT, cannot account for the correlations found between the observed tidal variability in the NH mesosphere and the SH SPW. Here our interpretation for the high correlation is that there is usually a similar seasonal dependence between the amplitudes of the NH SDT $\left(50 \sim 70^{\circ} \mathrm{N}\right)$ and SH SPW1, i.e., being small in early summer and then large in late summer and fall. The correlations are usually dominated by the low-frequency variability (usually $>25$ days) of the SDT and SPW1 amplitudes. The late summer and early autumn (August-September) enhancement of the SDT amplitude in the NH mesosphere is primarily a behaviour of a migrating tide caused by other mechanisms (e.g. the refractive effects suggested by Riggin et al., 2003) rather than the SPW-tidal interaction, while the growth of SPW activity in the SH stratosphere during austral late winter (August-October) is related to the breakdowns of the polar vortex and the final stratospheric warming in the SH. While these two events ( $\mathrm{SH}$ and $\mathrm{NH}$ ) may be distantly and physically related, at this stage of our understanding and until a model such as CMAM-DAS is used diagnostically, no such claims of inter-hemispheric coupling will here be claimed.
Further, if the correlations for the Troms $\varnothing$ and Saskatoon tides are due to the non-migrating contribution, then the observed Arctic tidal amplitudes at appropriate longitudes should have even better correlations with the SH SPW amplitudes since the relative contribution of the non-migrating tides are larger at Arctic latitudes. However, the SDT amplitudes observed at Svalbard $\left(78^{\circ} \mathrm{N}\right)$ and Eureka $\left(80^{\circ} \mathrm{N}\right)$ generally do not provide persistent significant correlations with the SPW1 amplitudes in the high latitude Southern Hemisphere for the two summer-fall seasons (Fig. 1; negative correlations for the Svalbard $94 \mathrm{~km}$ tide are statistical artefacts). Note that due to the longitudinal variation of the phase of the NMT the tidal amplitude modulation in the presence of non-migrating tides is different for stations at different longitudes. For example, Baumgaertner et al. (2006) showed in their Fig. 10 that at $78^{\circ} \mathrm{S}$ and $90 \mathrm{~km}$ altitude there is a preferred longitude (longitudinal maximum) for constructive interference between an $\mathrm{s}=2$ migrating SDT and an $\mathrm{s}=1$ nonmigrating SDT. Thus at this longitude (call it L) an $\mathrm{s}=1$ tide would cause an enhancement in the total unresolved SDT amplitude $(\mathrm{s}=1+\mathrm{s}=2)$, and an observed positive correlation with the SPW1 amplitude. Conversely at L+180 degrees longitude an $\mathrm{s}=1$ tide will cause a decrease in the total unresolved SDT, and an observed negative correlation with the SPW1. At longitudes of $\mathrm{L} \pm 90$ degrees there would be little observed effect. However, the situation is different for the $\mathrm{NH}$. Our analysis clearly indicated that at $\sim 80^{\circ} \mathrm{N}$ the migrating SDT is dominant and the non-migrating is weak for $\mathrm{NH}$ late-summer/early fall. Therefore, there should be no significant longitudinal variability for the observed SDT of Arctic latitudes assuming the $s=2$ SDT amplitude is unchanged. Indeed the height versus time contours of SDT amplitude ratios for Svalbard and Eureka (Fig. 8 of Manson et al., 2009) clearly show ratios near unity in late summer/early fall. Thus, the Arctic SDTs observed at other longitudes are expected to exhibit similar statistical results (i.e. no real correlations with the SH SPW). This further confirms the small effect of the SH SPW on the NH tidal variability in the NH summer-fall months. The SH-winter SPW is usually much weaker compared with their northern counterpart (this paper; Manson et al., 2009; van Loon and Jenne, 1972; Aso, 2007). This could be an important reason why the Antarctic-winter SPW's driving of the non-migrating SDT in the Arctic-summer is less significant, and thus less likely to be observed.

Note that although we think the local summer tidal variability in the NH is not physically associated with the growth of SPW activity in the opposite hemisphere, the global forcing of the non-migrating tide by the SPW is possible in October. Our analyses show that the dominance of nonmigrating tides usually first appears during this equinoctial time (October and onto November) while the simultaneous SPW amplitudes in both hemispheres are often comparable. Chshyolkova et al. (2006) have shown that inter-hemispheric propagation of planetary waves probably occurs during the equinox months, which enhances the possibility of NMT 


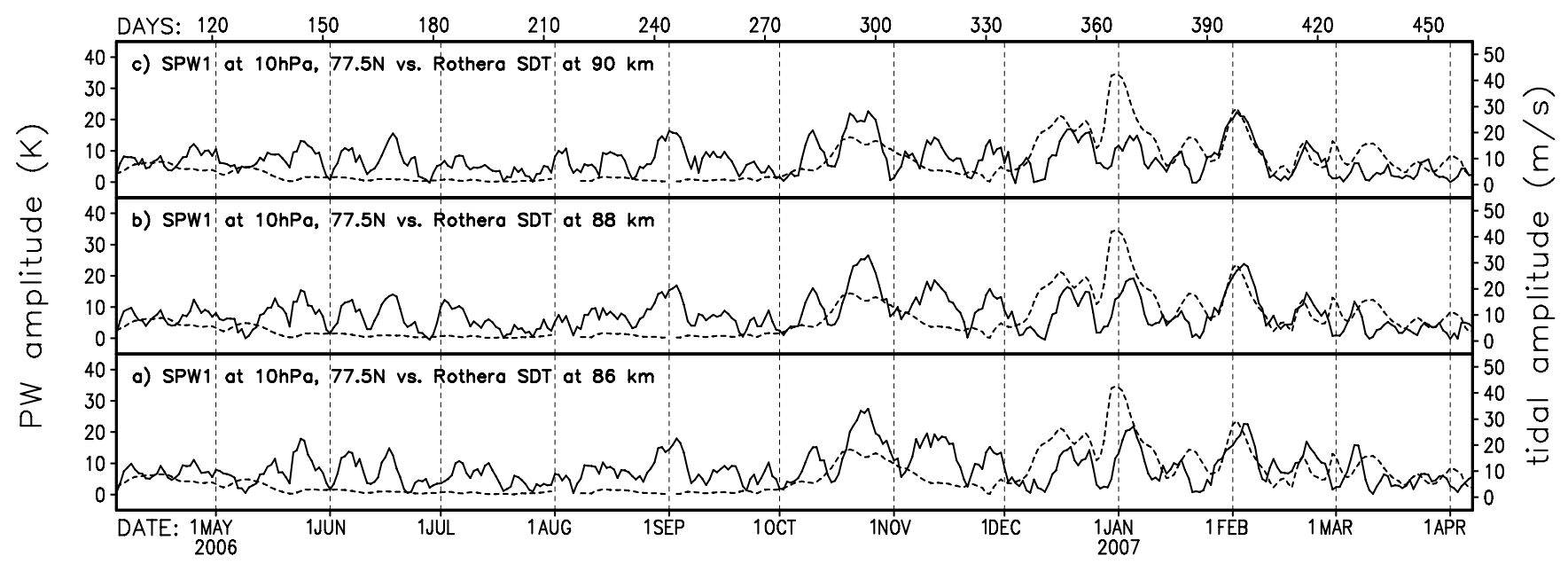

Fig. 12. Time sequences of the stationary planetary wave 1 amplitudes at $10 \mathrm{hPa}, 75-80^{\circ} \mathrm{N}$ (dashed line; scale on left axis, shown in all panels) versus the Rothera $\left(68^{\circ} \mathrm{S}, 68^{\circ} \mathrm{W}\right)$ meridional semidiurnal tide amplitudes (solid line; scale on right axis) at 86 (a), 88 (b) and $90 \mathrm{~km}$ (c) for $2006 / 2007$.

presence. However, this SPW-NMT link in October has a weak contribution to the 120-day correlation between the observed NH SDT and SH SPW1.

During NH winter-centred months (early November to early March), the mesospheric SDT amplitudes observed at northern middle/high latitudes $\left(\sim 50-80^{\circ} \mathrm{N}\right)$ are often observed to be significantly and positively correlated with the SPW1 amplitudes in the local hemisphere (Figs. 7 and 8). These correlations are also usually dominated by the lowfrequency variability (usually $>15$ days) for the SDT and SPW1 amplitudes. Because both the SPW and migrating SDT are often large in the NH during NH winter, the SPWMT non-linear interaction probably occurs in the $\mathrm{NH}$, providing the non-migrating $\mathrm{s}=1 \mathrm{SDT}$ which could then propagate into the $\mathrm{SH}$ and lead to the local summer enhancement of the $s=1$ NMT in the SH (e.g. January 2007 in Fig. 11, $58-87^{\circ} \mathrm{S}$ ). Our Fig. 2 shows that departure from MT dominance occurs spasmodically from mid-December through to April. Corresponding to this, the height versus time contours of SDT amplitude ratios for Svalbard and Eureka (Fig. 8 of Manson et al., 2009) clearly show large ratios for those months. That is consistent with the studies of Yamashita et al. (2002) and Baumgaertner et al. (2006), and suggested by Manson et al. (2009).

The aforementioned discussions reveal little evidence that the summer-fall variability of the Arctic SDT is associated with the Antarctic SPW of austral winter. In contrast, as noted above, during NH winter the Arctic SPW driving the Antarctic non-migrating SDT is possible (also Murphy et al., 2009). Figure 12 provides good agreement for the amplitude variability between the NH stratospheric SPW1 and the meridional SDT $(86-90 \mathrm{~km})$ observed at Rothera $\left(68^{\circ} \mathrm{S}, 68^{\circ} \mathrm{W}\right)$ during December-February of 2006/2007. The Rothera-correlations are consistent with this location being within a longitudinal maximum of the observed tide. The Arctic SPW amplitudes are generally much larger than those in the Antarctica during the winter of each hemisphere. So the Arctic SPW, via interacting with migrating tides, is more likely to account for the local summer enhancement of Antarctic non-migrating SDT.

This study does not explain what drives the high variability of the observed SDT, especially for the late-summer/early fall enhancement. This is a very complex subject. Riggin et al. (2003) listed various mechanisms and focused on the refractive effects. A detailed analysis for all possible sources of the tidal variability would require more efforts and is beyond the scope of this paper. In addition, note that some differences are shown in the correlation plots between the two years, which might be due to the effect of the quasibiennial oscillation (QBO) that has opposite phases in the two years (e.g. Espy et al.,1997; Jacobi et al., 1998; Hibbins et al., 2007). The relation between interannual variations in the SPW and tides has been presented in the most recent study (Xu et al., 2009).

\section{Conclusions}

The SDTs observed at $\mathrm{NH}$ high/Arctic latitudes failed to exhibit any real correlation with the Antarctic SPW1 in $\mathrm{NH}$ summer-fall, in contrast with the claims of Smith et al. (2007). The correlations for the Troms $\varnothing$ and Saskatoon tides are considered at this time to be due to the trends of the tides and SH SPW1 amplitudes during the respective equinoctial transitions. Although such individual trends will encompass physical processes that have a global dimension, without diagnostic assessment of an excellent GCM simple causality involving SPW and SDT cannot be provided 
at this point. During austral winter the PWs at Antarctic latitudes are usually weaker than their Arctic-winter counterpart, which possibly prevents the occurrence of strong wave-tide interactions and the generation of the non-migrating tides. The SH interaction driving the $\mathrm{NH}$ non-migrating tides might occur merely, for example, for the austral winter of 2002 that was historically unique due to the presence of a major SSW and unusually high PW activity. Conversely, during NH winters the PWs are often strong, which probably supports the extensive occurrence of strong SPW-migrating tide interaction. The latter could then, given good propagation conditions, lead to the summer enhancement of the NMT in the SH.

The "percentage power in the MT" from the pair of radars was used as an additional factor in the physical assessment of the correlation: a value close to $100 \%$ indicates the dominance of the MT, and smaller values indicate the increasing presence and at times dominance of NMT. This strategy was shown to be effective, as the MT was shown simply to be dominant in the Arctic from mid-summer to early fall. A reviewer had expressed concerns that the otherwise desirable "zonal wavenumber resolved NMT", which can be numerically obtained from radar pairs, may be problematic especially at non-Arctic latitudes. We discussed this matter in this paper, agreed to differ to some degree, but did not provide figures with NMT of particular wavenumber.

Acknowledgements. Funding for this work was from CANDACPEARL, in part from its IPY funding; the Canadian Natural Sciences and Engineering Research Council; and the University of Saskatchewan through support to ISAS. Thanks are given to the Aura team for their MLS dataset. T. Aso jointly supports the Svalbard radar data. The Rothera MF radar was jointly supported by National Science Foundation grant OPP-0438777 and by the UK Natural Environment Research Council. The authors are also grateful to the CMAM-DAS team for providing the CMAM-DAS data. The CMAM-DAS is funded by CFCAS and the CSA through the CSPARC project.

Editor in Chief W. Kofman thanks two anonymous referees for their help in evaluating this paper.

\section{References}

Angelats i Coll, M. and Forbes, J. M.: Nonlinear interactions in the upper atmosphere: the $\mathrm{s}=1$ and $\mathrm{s}=3$ nonmigrating semidiurnal tides, J. Geophys. Res., 107(A8), 1157, doi:10.1029/2001JA900179, 2002.

Aso, T.: A note on the semidiurnal non-migrating tide at polar latitudes, Earth Planets Space, 59, 21-24, 2007.

Baumgaertner, A. J. G., McDonald, A. J., Fraser, G. J., and Plank, G. E.: Long-term observations of mean winds and tides in the upper mesosphere and lower thermosphere above Scott Base, Antarctica, J. Atmos. Solar-Terr. Phys., 67(16), 1480-1496, 2005.

Baumgaertner, A. J. G., Jarvis, M. J., McDonald, A. J., and Fraser, G. J.: Observations of the wave number 1 and 2 components of the semi-diurnal tide over Antarctica, J. Atmos. Solar-Terr. Phys., 68(11), 1195-1214, 2006.

Chshyolkova, T., Manson, A. H., Meek, C. E., Avery, S. K., Thorsen, D., MacDougall, J. W., Hocking, W., Murayama, Y., and Igarashi, K.: Planetary wave coupling processes in the middle atmosphere $(30-90 \mathrm{~km})$ : a study involving MetO and MF radar data, J. Atmos. Solar-Terr. Phys., 68, 353-368, 2006.

Chshyolkova, T., Manson, A. H., Meek, C. E., Aso, T., Avery, S. K., Hall, C. M., Hocking, W., Igarashi, K., Jacobi, C., Makarov, N., Mitchell, N., Murayama, Y., Singer, W., Thorsen, D., and Tsutsumi, M.: Polar vortex evolution during Northern Hemispheric winter 2004/05, Ann. Geophys., 25, 1279-1298, 2007, http://www.ann-geophys.net/25/1279/2007/.

Cierpik, K. M., Forbes, J. M., Miyahara, S., Miyoshi, Y., Fahrutdinova, A., Jacobi, C., Manson, A. H., Meek, C., Mitchell, N. J., and Portnyagin, Y.: Longitude variability of the solar semidiurnal tide in the lower thermosphere through assimilation of groundand space-based wind measurements, J. Geophys. Res., 108(A5), 1202, doi:10.1029/2002JA009349, 2003.

Ebisuzaki, W.: A method to estimate the statistical significance of a correlation when the data are serially correlated, J. Climate, 10, 2147-2153, 1997.

Espy, P. J., Stegman, J., and Witt, G.: Interannual variations of the quasi-16-day oscillation in the polar summer mesospheric temperature, J. Geophys. Res., 102(D2), 1983-1990, 1997.

Forbes, J. M., Makarov, N. A., and Portnyagin, Y.: First results from the Meteor radar at South-pole - A large 12-hour oscillation with zonal wave-number one, Geophys. Res. Lett., 22(23), 32473250, 1995.

Forbes, J. M. and Wu, D.: Solar tides as revealed by measurements of mesosphere temperature by the MLS experiment on UARS, J. Atmos. Sci., 63(7), 1776-1797, 2006.

Hagan, M. E. and Roble, R. G.: Modeling diurnal tidal variability with the National Center for Atmospheric Research thermosphere-ionosphere-mesosphere-electrodynamics general circulation model, J. Geophys. Res.-Space Phys., 106(A11), 24869-24882, 2001.

Hall, C. M., Aso, T., Tsutsumi, M., Nozawa, S., Manson, A. H., and Meek, C. E.: A comparison of mesosphere and lower thermosphere neutral winds as determined by meteor and medium-frequency radar at $70^{\circ} \mathrm{N}$, Radio Sci., 40, RS4001, doi:10.1029/2004RS003102, 2005.

Hernandez, G., Fraser, G. J., and Smith, R. W.: Mesospheric 12-hour oscillation near South-pole, Antarctica, Geophys. Res. Lett., 20(17), 1787-1790, 1993.

Hibbins, R. E., Espy, P. J., and Jarvis, M. J.: Quasi-biennial modulation of the semidiurnal tide in the upper mesosphere above Halley, Antarctica, Geophys. Res. Lett., 34, L21804, doi:10.1029/2007GL031282, 2007.

Jacobi, Ch., Schminder, R., and Kurschner, D.: Long-period (1225 days) oscillations in the summer mesopause region as measured at Collm $\left(52^{\circ} \mathrm{N}, 15 \mathrm{oE}\right)$ and their dependence on the equatorial quasi-biennial oscillation, Contributions to Atmospheric Physics, 71, 461-464, 1998.

Jacobi, Ch., Portnyagin, Y. I., Solovjova, T. V., et al.: Climatology of the semidiurnal tide at $52-56 \mathrm{oN}$ from ground-based radar wind measurements 1985-1995, J. Atmos. Solar Terr. Phys., 61, 975991, 1999.

Jacobi, Ch., Arras, C., Kurschner, D., Singer, W., Hoffmann, P., 
and Keuer, D.: Comparison of mesopause region meteor radar winds, medium frequency radar winds and low frequency drifts over Germany, Adv. Space Res., 43, 247-252, 2009.

Leovy, C. B. and Webster, P. J.: Stratospheric long waves: comparison of thermal structure in the Northern and Southern Hemisphere, J. Atmos. Sci., 33, 1624-1638, 1976.

Manson, A. H., Meek, C., Hagan, M., Zhang, X., and Luo, Y.: Global distributions of diurnal and semidiurnal tides: observations from HRDI-UARS of the MLT region and comparisons with GSWM-02 (migrating, nonmigrating components), Ann. Geophys., 22, 1529-1548, 2004a,

http://www.ann-geophys.net/22/1529/2004/.

Manson, A. H., Meek, C. E., Chshyolkova, T., Avery, S. K., Thorsen, D., MacDougall, J. W., Hocking, W., Murayama, Y., Igarashi, K., Namboothiri, S. P., and Kishore, P.: Longitudinal and latitudinal variations in dynamic characteristics of the MLT (70-95 km): a study involving the CUJO network, Ann. Geophys., 22, 347-365, 2004b,

http://www.ann-geophys.net/22/347/2004/.

Manson, A. H., Meek, C. E., Hall, C. M., Nozawa, S., Mitchell, N. J., Pancheva, D., Singer, W., and Hoffmann, P.: Mesopause dynamics from the scandinavian triangle of radars within the PSMOS-DATAR Project, Ann. Geophys., 22, 367-386, 2004c, http://www.ann-geophys.net/22/367/2004/.

Manson, A. H., Meek, C., Chshyolkova, T., McLandress, C., Avery, S. K., Fritts, D. C., Hall, C. M., Hocking, W. K., Igarashi, K., MacDougall, J. W., Murayama, Y., Riggin, C., Thorsen, D., and Vincent, R. A.: Winter warmings, tides and planetary waves: comparisions between CMAM (with interactive chemistry) and MFR-MetO observations and data, Ann. Geophys., 24, 24932518, 2006, http://www.ann-geophys.net/24/2493/2006/.

Manson, A. H., Meek, C. E., Chshyolkova, T., Xu, X., Aso, T., Drummond, J. R., Hall, C. M., Hocking, W. K., Jacobi, Ch., Tsutsumi, M., and Ward, W. E.: Arctic tidal characteristics at Eureka $\left(80^{\circ} \mathrm{N}, 86^{\circ} \mathrm{W}\right)$ and Svalbard $\left(78^{\circ} \mathrm{N}, 16^{\circ} \mathrm{E}\right)$ for $2006 / 07$ : seasonal and longitudinal variations, migrating and non-migrating tides, Ann. Geophys., 27, 1153-1173, 2009,

http://www.ann-geophys.net/27/1153/2009/.

Mitchell, N. J., Pancheva, D., Middleton, H. R., and Hagan, M. E.: Mean winds and tides in the Arctic mesosphere and lower thermosphere, J. Geophys. Res., 107(A1), 1004, doi:10.1029/2001JA900127, 2002.

Miyahara, S. and Miyoshi, Y.: Migrating and non-migrating atmospheric tides simulated by a middle atmosphere general circulation model, Adv. Space Res., 20, 1201-1207, 1997.

Miyahara, S., Miyoshi, Y., and Yamashita, K.: Variations of migrating and nonmigrating tides simulated by the middle atmosphere circulation model at Kyushu University, Adv. Space Res., 24, 1549-1558, 1999.

Murphy, D. J.: Variations in the phase of the semidiurnal tide over Davis, Antarctica, J. Atmos. Solar-Terr. Phys., 64(8-11), 10691081, 2002.

Murphy, D. J., Forbes, J. M., Walterscheid, R. L., Hagan, M. E., Avery, S. K., Aso, T., Fraser, G. J., Fritts, D. C., Jarvis, M. J., McDonald, A. J., Riggin, D. M., Tsutsumi, M., and Vincent, R. A.: A climatology of tides in the Antarctic mesosphere and lower thermosphere, J. Geophys. Res.-Atmos., 111(D23), D23104, doi:10.1029/2005JD006803, 2006.
Murphy, D. J., Aso, T., Fritts, D. C., Hibbins, R. E., McDonald, A. J., Riggin, D. M., Tsutsumi, M., and Vincent, R. A.: Source regions for Antarctic MLT non-migrating semidiurnal tides, Geophys. Res. Lett., 36, L09805, doi:10.1029/2008GL037064, 2009.

Oberheide, J., Wu, Q., Killeen, T. L., Hagan, M. E., and Roble, R. G.: A climatology of nonmigrating semidiurnal tides from TIMED Doppler Interferometer (TIDI) wind data, J. Atmos. Solar-Terr. Phys., 69(17-18), 2203-2218, 2007.

Polavarapu, S. M., Ren, S., Rochon, Y., Sankey, D., Ek, N., Koshyk, J., and Tarasick, D.: Data assimilation with the Canadian Middle Atmosphere Model, Atmos.-Ocean, 43, 77-100, 2005.

Portnyagin, Y. I., Forbes, J. M., Makarov, N. A., Merzlyakov, E. G., and Palo, S.: The summertime 12-h wind oscillation with zonal wavenumber $s=1$ in the lower thermosphere over the South Pole, Ann. Geophys., 16, 828-837, 1998,

http://www.ann-geophys.net/16/828/1998/.

Portnyagin, Y. I., Forbes, J. M., Merzlyakov, E. G., Makarov, N. A., and Palo, S. E.: Intradiurnal wind variations observed in the lower thermosphere over the South Pole, Ann. Geophys., 18, 547-554, 2000,

http://www.ann-geophys.net/18/547/2000/.

Portnyagin, Y. I., Solovjova, T. V., Makarov, N. A., Merzlyakov, E. G., Manson, A. H., Meek, C. E., Hocking, W., Mitchell, N., Pancheva, D., Hoffmann, P., Singer, W., Murayama, Y., Igarashi, K., Forbes, J. M., Palo, S., Hall, C., and Nozawa, S.: Monthly mean climatology of the prevailing winds and tides in the Arctic mesosphere/lower thermosphere, Ann. Geophys., 22, 33953410, 2004, http://www.ann-geophys.net/22/3395/2004/.

Riggin, D. M., Fritts, D. D., Jarvis, M. J., and Jones, G. O. L.: Spatial structure of the 12-hour wave in the Antarctic as observed by radar, Earth Planets Space, 51, 621-628, 1999.

Riggin, D. M., Meyer, C. K., Fritts, D. C., Jarvis, M. J., Murayama, Y., Singer, W., Vincent, R. A., and Murphy, D. J.: MF radar observations of seasonal variability of semidiurnal motions in the mesosphere at high northern and southern latitudes, J. Atmos. Solar-Terr. Phys., 65(4), 483-493, 2003.

Smith, A. K., Pancheva, D. V., Mitchell, N. J., Marsh, D. R., Russell III, J. M., and Mlynczak, M. G.: A link between variability of the semidiurnal tide and planetary waves in the opposite hemisphere, Geophys. Res. Lett., 34, L07809, doi:10.1029/2006GL028929, 2007.

Usoskin, I. G., Voiculescu, M., Kovaltsov, G. A., and Mursula, K.: Correlation between clouds at different altitudes and solar activity: Fact or Artifact?, J. Atmos. Solar-Terr. Phys., 68, 21642172, 2006.

van Loon, H. and Jenne, R. L.: The zonal harmonic standing waves in the Southern Hemisphere, J. Geophys. Res., 77, 3846-3855, 1972.

Xu, X., Manson, A. H., Meek, C. E., et al.: Asymmetry in the interhemispheric planetary wave-tide link between the two hemispheres, J. Atmos. Solar-Terr. Phys., in press, doi:10.1016/j.jastp.2009.07.011, 2009.

Yamashita, K., Miyahara, S., Miyoshi, Y., Kawano, K., and Ninomiya, J: Seasonal variation of non-migrating semidiurnal tide in the polar MLT region in a general circulation model, J. Atmos. Solar-Terr. Phys., 64, 1083-1094, 2002. 